OPEN ACCESS

Edited by:

Sergi Astals,

University of Barcelona, Spain

Reviewed by:

Lucas Vassalle,

Federal University of Minas Gerais,

Brazil

Cesar Huilininir Curío,

University of Santiago, Chile

*Correspondence:

Stefan Junne

stefan.junne@tu-berlin.de

Specialty section:

This article was submitted to Environmental Chemical Engineering,

a section of the journal

Frontiers in Chemical Engineering

Received: 19 May 2021

Accepted: 18 August 2021

Published: 01 September 2021

Citation:

Janesch E, Pereira J, Neubauer $P$ and Junne $S$ (2021) Phase Separation in Anaerobic Digestion: A Potential for

Easier Process Combination?

Front. Chem. Eng. 3:711971.

doi: 10.3389/fceng.2021.711971

\section{Phase Separation in Anaerobic Digestion: A Potential for Easier Process Combination?}

\author{
Eike Janesch, Joana Pereira, Peter Neubauer and Stefan Junne* \\ Bioprocess Engineering, Department of Biotechnology, Technische Universität Berlin, Berlin, Germany
}

The flexibilization of bioenergy production has the potential to counteract partly other fluctuating renewable energy sources (such as wind and solar power). As a weatherindependent energy source, anaerobic digestion (AD) can offer on-demand energy supply through biogas production. Separation of the stages in anaerobic digestion represents a promising strategy for the flexibilization of the fermentative part of biogas production. Segregation in two reactor systems facilitates monitoring and control of the provision of educts to the second methanogenic stage, thus controlling biogas production. Two-stage operation has proven to reach similar or even higher methane yields and biogas purities than single-stage operation in many different fields of application. It furthermore allows methanation of green hydrogen and an easier combination of material and energy use of many biogenic raw and residual biomass sources. A lot of research has been conducted in recent years regarding the process phase separation in multi-stage $A D$ operation, which includes more than two stages. Reliable monitoring tools, coupled with effluent recirculation, bioaugmentation and simulation have the potential to overcome the current drawbacks of a sophisticated and unstable operation. This review aims to summarize recent developments, new perspectives for coupling processes for energy and material use and a system integration of AD for power-to-gas applications. Thereby, cell physiological and engineering aspects as well as the basic economic feasibility are discussed. As conclusion, monitoring and control concepts as well as suitable separation technologies and finally the data basis for techno-economic and ecologic assessments have to be improved.

Keywords: two-stage digestion, feedstock flexibilization, methanation, on-demand production, bioprocess coupling

\section{INTRODUCTION}

Flexible biogas production via anaerobic digestion (AD) can complement the energy production by fluctuating renewable wind and solar energy sources, which are typically affected by seasonality (Peters et al., 2018). Additionally, the use of biogenic residues for biogas production, such as agricultural and forestry by-products and industrial as well as municipal residues encourages the implementation of circular bioeconomy concepts, while facilitating solid waste management. The competition for the utilization of natural resources, polluting emissions, and feedstock costs are reduced (Atasoy et al., 2018; Theuerl et al., 2019). In order to increase the potential of existing AD processes without multiplying the investment costs required for the installation of on-site gas storage, the fermentation itself can be operated dynamically. This can be achieved by using varying amounts 


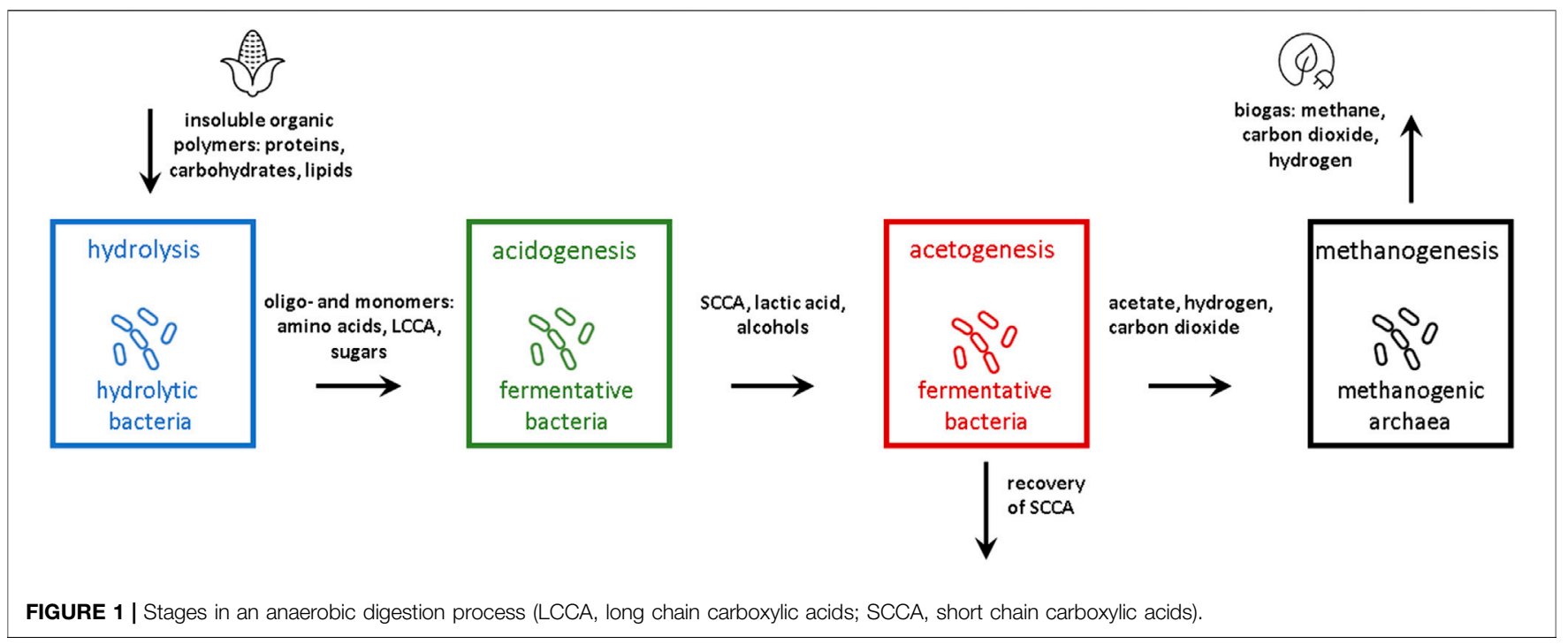

of feedstock or alternating the feedstock sources. One promising approach to increase the flexibilization of the production rates is represented by process-phase separation. Hereby, the ideal conditions for every process phase can be controlled separately in each stage. Additionally, a coupling of energy and material use of various biogenic resources becomes feasible.

The advantages and disadvantages of phase separation in $\mathrm{AD}$ have been described in several research papers and reviews e.g. from Chatterjee and Mazumder (2019), Van et al. (2020) or Menzel et al. (2020). The present work aims to complement previous research on the topic, by highlighting the value-adding possibilities which can result from coupling the hydrolytic/ acidogenic with the methanogenic stage of $\mathrm{AD}$. The synergies obtained from phase separation and effluent recirculation in $\mathrm{AD}$ are discussed as means for the achievement of stable, affordable, and sustainable energy production. Furthermore, the potential for achieving value-added products beside biogas is highlighted. Challenges remain though, such as process disturbances caused by the overgrowth of phase-specific microorganisms brought in from feedstock, effects of inhibitors and the achievement of individual suitable feeding rates of substrates and co-factors at each process stage. Such hurdles can be minimized by improved process controllability and predictability, which can be achieved via improved process monitoring, which includes cell viability measures and, if known, the quick detection of potential inhibitors. Recent developments in this field are described in this review as they can support a robust operation in multi-stage AD. Additionally, a comprehensive summary of the recent approaches for flexible biogas production coupled with biological methanation or other bioprocesses is presented.

\section{PHASES OF ANAEROBIC DIGESTION}

$\mathrm{AD}$ is a complex process, in which various microorganisms are involved in degrading organic substrates under anaerobic conditions. In brief, $\mathrm{AD}$ is typically described with four metabolic phases as shown in Figure 1. In the first step - the hydrolysis - biomass which usually consists of insoluble organic polymers like proteins, lipids and carbohydrates is degraded by hydrolytic bacteria into soluble oligo- and monomers (Kaltschmitt et al., 2016; Rabii et al., 2019). Hydrolysis often acts as the bottleneck in $\mathrm{AD}$ processes as it demands a combination of enzymes and time to break the complex molecule structures of the substrate to overcome the steric hindrance. Mechanical, thermal, chemical, and biological pretreatment processes, as well as combinations thereof, have been reviewed and assessed for their potential to increase the efficiency of $\mathrm{AD}$ and shorten process times, e.g. in (Ariunbaatar et al., 2014). In order to access the high-molecular, sterically blocked substances, microorganisms use exoenzymes like hydrolases. Most of these facultative anaerobic or strictly anaerobic hydrolytic microorganisms are very resilient against varying chemical and physical conditions. A recent review focused on the hydrolytic process stage in depth (Menzel et al., 2020) among other previous reports.

In the second phase of $\mathrm{AD}$, denoted as acidogenesis, fermentative bacteria degrade the resulting substances from the hydrolysis into low-molecular intermediates like amino acids, short-chain carboxylic acids (SCCAs), and alcohols. A description of the role of microbes within typical digestion consortia were summarized in Rabii et al. (2019).

In the next step, the acetogenesis, the intermediates from the acidogenesis are converted into acetic acid. Depending on the available substances, different ratios of acetic acid, carbon dioxide and hydrogen are formed by acetogenic bacteria like Acetobacterium or Clostridium species (Borja, 2011). The hydrolytic/acidogenic stage, eventually exhibiting acetogenic conversions, is also called dark fermentation (DF) or acid fermentation and typically operated with HRT of several days only (Rosgaard et al., 2007; Menzel et al., 2020; Van et al., 2020). A $\mathrm{pH}$-value of about 5.0 up to 6.0 is optimal, while a lower $\mathrm{pH}$-value can lead to increased retention time; alkaline $\mathrm{pH}$ values may totally inhibit the process (Zhang et al., 2005; Moestedt et al., 2016). 
In the final step of $\mathrm{AD}$, strictly anaerobic methanogenic archaea transform hydrogen together with acetic acid and carbon dioxide into methane. In comparison to this conversion, that is restricted to a small group of microorganisms inside the archaea domain, the hydrogenotrophic methanogenesis is conducted by a wide variety of species as reviewed recently (Kaltschmitt et al., 2016; Castellano-Hinojosa et al., 2018; Rabii et al., 2019). In this case, the reduction of carbon dioxide with hydrogen leads to the formation of methane. Growth of acetogens and methanogens is favored by mesophilic conditions and neutral $\mathrm{pH}$-values. Since the anaerobic archaea show the slowest growth among most of the microbes in $\mathrm{AD}$, they are the most fragile towards varying conditions and the presence of inhibitors like ammonia. Thus, in the widespread use of single-stage $\mathrm{AD}$ applications, the physical and chemical parameters of the system are adjusted in favor to keep these organisms vital (Van et al., 2020). Typical representatives of archaea in biogas fermenters are described in more detail by Wirth et al. (2012).

\section{POTENTIALS OF PHASE SEPARATION}

Reactor types used in $\mathrm{AD}$ are typically continuously operated stirred tank reactors (STRs), upflow anaerobic sludge blankets (UASB) and plug-flow reactors (PFRs); the first two reactor designs are typically used for multi-stage $\mathrm{AD}$. A lot of $\mathrm{AD}$ applications with UASBs can be found in tropical countries. These reactors benefit from their potential to handle high organic loading rates and their longevity and robustness due to the lack of moving parts like stirrers (Bischofsberger, 2005).

In the dominant single-stage stirred tank biogas reactors, all process phases are conducted in parallel. Beside the advantage of an intercellular hydrogen transfer, also some disadvantages of such a system exist: high loads of organic substrate or a sudden change in the feedstock composition can lead to acidification, when the hydrolytic and acidogenic or acetogenic reactions dominate and are conducted faster than the acid consumption by the acetoclastic organisms. This can lead to severe failures in fermentation and considerable down times (Moeller and Zehnsdorf, 2016). Although no detailed data about this has been published, the dominance of STRs over plug-flow reactors PFRs, in which a separation of phases is achieved due to the nature of the low axial mixing, is also caused by higher investment costs of the latter reactor technology. It is still not fully proven, however, if a PFR concept exhibits a higher robustness against flexible feedstock loads than a STR design due to the many possibilities of feedstock and operational conditions in the numerous published studies. Multi-stage $\mathrm{AD}$ applications, however, aim to combine some of the advantages of stirred tank and plug-flow concepts.

Theoretically, all four phases of $\mathrm{AD}$ can be divided and conducted in different reactors. Most of the hydrolytic and acidogenic bacteria, however, share similar optimal growth conditions. Generally, these are represented by mesophilic or thermophilic microbes, whose maximum growth is reached at slightly acidic pH-values of between 4.5 and 6.0. Aceto- and methanogens prefer neutral $\mathrm{pH}$-values between 6.5 and 7.5. Thus, they differ in their nutritional demands, growth kinetics and temperature preferences compared to the hydrolytic and acidogenic microorganisms (Van et al., 2020). In multi-stage $\mathrm{AD}$ processes, it becomes feasible to adjust the process parameters individually in each part of the reactor. Therefore, such a process design does not compromise as much between the different growth requirements of the microbes as in single-stage $\mathrm{AD}$. In a typical multi-stage $\mathrm{AD}$, the first stage comprises mostly of hydrolytic and acidogenic microorganisms while the subsequent stages contain mainly acetogenic and methanogenic microorganisms. By monitoring and controlling the $\mathrm{pH}$-value, it is possible to separate these phases from each other with a low effort (Chatterjee and Mazumder, 2019; Van et al., 2020).

Phase separation has proven to be beneficial to produce hydrogen-enriched biogas $(10-30 \% \mathrm{v} / \mathrm{v})$ with a profitable process (Dahiya et al., 2018). An AD process with phase separation can facilitate on-demand biogas production because the products of the hydrolysis can be added dynamically to the methanogenic stage. This way, the methane production can be enhanced for a certain time, e.g. by about 60\% (Linke et al., 2015). Leftover nutrients in the digestate can be used as biofertilizer, containing nitrogen in inorganic form (often over $60 \%(\mathrm{w} / \mathrm{w})$ of total nitrogen), phosphorus, and potassium, characterized by a high bioavailability (Chojnacka et al., 2020). A separate hydrolytic/acidogenic stage can save costs as other feedstock pre-treatment becomes useless (Blank and Hoffmann, 2011).

The phyla Proteobacteria, Bacteroidetes, Firmicutes and Chloroflexi can typically be found in $\mathrm{AD}$ broths (Jie et al., 2014; Liu et al., 2014; Wu et al., 2016). These bacteria possess a higher natural resilience against disturbances and fluctuating process conditions than methanogens (Kaltschmitt et al., 2016). When the first stage of an $\mathrm{AD}$ application is not dependent on the viability of methanogens due to separated phases, the whole process can gain more stability against a varying organic loading rate (OLR) and chemical inhibitors like oxygen, ammonia, and toxins, that are brought into the process by feedstock feeding. While different fermentation variants exist, like acetic-, butyric-, ethanol- or mixed-hydrolysis, Menzel et al. (2020) consider acetic and butyric fermentation as most suitable for multi-stage $\mathrm{AD}$ applications. This type of fermentation is favored under thermophilic conditions at $\mathrm{pH}$-values of between 5.0 and 6.0. Bacteria of the genus Clostridium release acetic and butyric acid and yields a biodegradability of up to $95 \%$ for the treatment of FW and rice straw in CSTR (Sträuber et al., 2012; Chen et al., 2015). The metabolic activity of hydrolytic and acidogenic microorganisms is only inhibited at higher concentrations of SCCAs beyond $10 \mathrm{~g} / \mathrm{L}$ or more; much higher concentrations than it is usually the case for methanogens (Zhang et al., 2017; Chatterjee and Mazumder, 2019).

$\mathrm{AD}$ is typically operated under either mesophilic $\left(35-39^{\circ} \mathrm{C}\right)$ or thermophilic conditions $\left(50-60^{\circ} \mathrm{C}\right)$. While thermophilic $\mathrm{AD}$ provides shorter HRT, digestion under mesophilic conditions is commonly considered as a slower, but rather stable process (Van et al., 2020) with lower energy costs (Fernández-Rodríguez et al., 2016). A combination of hydrolysis and acidogenesis in a 
TABLE 1 | Characteristics of stage separation in anaerobic digestion.

\begin{tabular}{|c|c|c|c|}
\hline Application & Advantages & Disadvantages & Typical process arrangement \\
\hline Single-stage & $\begin{array}{l}\text { - Low costs } \\
\text { - Applicable for very high/low TS- } \\
\text { contents } \\
\text { - Established process }\end{array}$ & $\begin{array}{l}\text { - Risk of quick acidification } \\
\text { - Repression of methanogens by inhibitors from the substrate } \\
\text { (e.g. } \mathrm{NH}_{3} \text { ) } \\
\text { - Risk of bacterial overgrowth } \\
\text { - No recovery of side products }\end{array}$ & $\begin{array}{l}\text { Hydrolysis/acidogenesis/acetogenesis/ } \\
\text { methanogenesis }\end{array}$ \\
\hline Two-stage & $\begin{array}{l}\text { - Recovery of side products } \\
\text { - Temperature-phased }\end{array}$ & $\begin{array}{l}\text { - High costs } \\
\text { - Not efficient for high TS-contents } \\
\text { - Disturbed intercellular hydrogen exchange }\end{array}$ & $\begin{array}{l}\text { 1. Stage: hydrolysis/acidogenesis } \\
\text { 2. Stage: acetogenesis/methanogenesis }\end{array}$ \\
\hline Three-stage & $\begin{array}{l}\text { - Recovery of side products } \\
\text { - High hydrolysis efficiency } \\
\text { - Shock load resistant }\end{array}$ & $\begin{array}{l}\text { - Very high costs and operational effort } \\
\text { - Lack of research on pilot scale } \\
\text { - Disturbed intercellular hydrogen exchange }\end{array}$ & $\begin{array}{l}\text { 1. Stage: hydrolysis/acidogenesis } \\
\text { 2. Stage: acidogenesis } \\
\text { 3. Stage: acetogenesis/methanogenesis }\end{array}$ \\
\hline
\end{tabular}

separate stage offers the possibility of temperature-gradients between the stages. This is of particular importance for the treatment of residues with high solid-contents like organic fractions of municipal solid waste (OFMSW) (FernándezRodríguez et al., 2016). Thermophilic operation, on the other side, promotes the deactivation of infectious pathogens as present in biogenic residues (Zhao and Liu, 2019). According to Pandey and Soupir (2011), the inactivation rate of Escherichia coli, as a representative for pathogenic organisms is 15 -fold higher at $52^{\circ} \mathrm{C}$ than at $37^{\circ} \mathrm{C}$. Fernández-Rodríguez et al. (2016) showed an application with up to $34 \%$ higher removal rates of VS and increased methane production in a two-phase $\mathrm{AD}$ operated with temperature combinations. By this a compromise between a purely mesophilic or thermophilic operation is made.

In order to achieve new opportunities for a flexible feedstock load and for demand-driven biogas production, research has been performed on multi-stage $\mathrm{AD}$, especially in two-stage concepts. Several strategies and scenarios have been described, in which existing plant infrastructure is re-engineered to increase the production flexibility within multi-stage concepts. Other publications have reviewed some of these aspects regarding the OFMSW (Chatterjee and Mazumder, 2019) and food waste (FW) (Srisowmeya et al., 2020), as well as for process configurations (Van et al., 2020) and mixed gas production(Hans and Kumar, 2019). Rajendran and co-authors focused on techno-economic assessments and related investments and operational costs under the consideration of mono-digester plants (Rajendran et al., 2020).

Typical characteristics of multi-stage AD are summarized in Table 1. The following chapters will further describe recent advances in more detail, including potential strategies to increase process robustness with monitoring and control tools, and the systemic integration into energy and biomaterial production grids.

\section{TWO-STAGE ANAEROBIC DIGESTION}

Two-stage AD is the most widely studied design within multiphase processes. Recent work focused on operational optimization and the application of feedstock that is difficult to be degraded. Li et al. (2017) published results for an OFMSW treatment with a two-phase AD application. A setup of three $20 \mathrm{~L}$ STRs was used, the first two for the combination of hydrolysis and acidogenesis, similar to the first stage of a two-stage anaerobic digester. While the single-stage operation achieved a biogas production of $540 \mathrm{ml} / \mathrm{g}-\mathrm{VS}$, the two-stage process reached $710 \mathrm{ml} / \mathrm{g}-\mathrm{VS}$ at a $30 \%$ higher OLR. The results of this study show that two-stage $\mathrm{AD}$ is not necessarily better than a singlestage $\mathrm{AD}$ in terms of substrate-specific biogas production yields, but might offer the possibility of higher loading and production rates. The net energetic production of a two-stage anaerobic digester for a substrate mixture consisting of whey and glycerine was compared to a single-stage system by Lovato et al. (2020). The authors concluded that the energy production from the two-stage $\mathrm{AD}\left(7.0 \mathrm{MJ} / \mathrm{kg}-\mathrm{COD}_{\text {removed }}\right)$ makes it profitable. Ghanimeh et al. (2019) investigated the biogas production performance of a single- (STR, 9L) and a two-stage thermophilic anaerobic digester. The two-stage digester showed better overall degradation rates and better biogas quality: at an average OLR between 2.0 and $2.4 \mathrm{~g}-\mathrm{VS} /(\mathrm{L} \cdot \mathrm{d})$, the reduction of total COD was nearly $80 \%$ higher in the multi-stage process compared to the mono-digester. The methane content of the biogas reached 45 and $54 \%$ in the single- and two-stage process design, respectively (Ghanimeh et al., 2019).

Two-stage $\mathrm{AD}$ has the potential to produce desulfurized biogas without a subsequent (external) desulfurization. The first stage of the $\mathrm{AD}$ application is controlled to favor the coexistence of acidogenic and sulfate reducing bacteria. A sulfate reduction in the first stage consequently reduces the hydrogen sulfide $\left(\mathrm{H}_{2} \mathrm{~S}\right)$ production in the methanogenic stage (Tijani et al., 2018). Yun et al. (2017) were able to reduce the $\mathrm{H}_{2} \mathrm{~S}$-content in the biogas in a two-stage AD system (STR, UASB) by nearly $90 \%$, compared to a conventional single-stage digester. The first stage of their application acted as a sulfidogenicacidogenic-reactor with a sulfate reduction of $70 \%$ at an optimum $\mathrm{pH}$-value of 5.5. As a model substrate, the authors used glucose combined with sodium sulfate (Yun et al., 2017). Similar results were described by Tijani et al. (2018), who examined the desulfurization of biogas in a two-stage system consisting of a shear-loop anaerobic bed and an anaerobic PFR for the treatment of palm oil mill waste. They considered 
a $\mathrm{pH}$-value of 5.4 as optimal for the sulfidogenic-acidogenic stage. The first stage of their application was able to reduce the sulfate by $75 \%$, and the biogas from the methanogenic stage was suitable for electricity production without $\mathrm{H}_{2} \mathrm{~S}$ removal (Tijani et al., 2018). Flores-Cortés et al. (2021) used a two-stage anaerobic nitratereducing bioreactor to desulfurize $\mathrm{H}_{2} \mathrm{~S}$-rich biogas; $95 \%$ of $\mathrm{H}_{2} \mathrm{~S}$ was oxidized.

As described before, depending on the substrate, two-stage operation can, beside other benefits, reach higher energy production, methane yields and methane ratios in the biogas within shorter HRT than single-staged processes in different pilot-scale studies, e.g. for the thermophilic treatment of the OFMSW (Ghanimeh et al., 2019) or the digestion of food waste (FW) (Gioannis et al., 2017). There is, however, still room for improvement. One major challenge is the interspecies-hydrogen transfer. The hydrogen produced by the acidogens is released in a different tank than the one with the hydrogen-consuming methanogens, that make use of it. As hydrogen has a very low solubility in water, it has to be ensured that enough hydrogen is dissolved in the second stage of two-stage $\mathrm{AD}$ or hydrogen has to be released in the off-gas, thus lowering the carbon dioxide binding capacity of the biological methanation. High-pressure two-stage AD represents an approach to enrich biogas with methane, without the need for external purification. Merkle et al. (2017) investigated the influence of high pressure up to 50 bar on a twostage $\mathrm{AD}$ application, consisting of a leach bed reactor and an anaerobic filter, fed with maize and grass silage. The methanogenic reactor was operated at $37^{\circ} \mathrm{C}$, an OLR of between 4.2 and $4.4 \mathrm{~g}-\mathrm{COD} /(\mathrm{L} \cdot \mathrm{d}), \mathrm{pH}$-values of about 6.6 and pressures of 10, 25 and 50 bar. While the specific methane yield decreased from 0.33 to $0.04 \mathrm{~L} /(\mathrm{g}$-COD) with an increased pressure from 10 to 50 bar, the methane content in the biogas increased by $11 \%$ (to finally $90 \%$ ) under these conditions. As a result, the biogas could be transferred directly into the gas grid without additional purification or pressurization (Merkle et al., 2017). Lemmer et al. (2015) have also reported an increase in the methane content from 70 to $77 \%$ when increasing the pressure from 1 to 9 bar in a two-stage AD composed by a leach bed reactor for a separate acidogenesis at $55^{\circ} \mathrm{C}$, and a methanogenic stage at $37^{\circ} \mathrm{C}$ at an OLR of $5 \mathrm{~g}-\mathrm{COD} /(\mathrm{L} \cdot \mathrm{d})$ of maize and grass silage. The application of high pressure in two-stage $\mathrm{AD}$ systems leads, however, to a decreasing $\mathrm{pH}$-value, which consequently effects the methane production negatively (Lemmer et al., 2015). Thus, Lemmer et al. (2015) tested, if a higher ammonium content in the methanogenic stage can counteract this issue by rising the buffer capacity. While the methane content of the biogas rose, the specific biogas yield decreased.

Furthermore and most important, concepts for an easy and cheap achievement of a two-stage process at existing biogas plants have to be accomplished, since the yearly numbers of new plants is slowing down (European Biogas Association, 2019). The "ReBi 2.0" (variable biogas production) from the Fraunhofer IEE represents a concept for upgrading existing biogas plants into variable biogas producers, which relies on the use of effluents enriched with SCCAs in the methanogenesis. After a hydrolytic stage, a phase separator enables the storage of the SCCAs-rich liquid in a storage tank. The solid effluents are digested in a conventional fermenter for continuous biogas production. The easily degradable SCCAs in turn are transferred to a fixed bed reactor, depending on the current demand of biogas. Experiments in a large-scale facility provided promising results with amounts of up to $70 \%(\mathrm{v} / \mathrm{v})$ of methane in the biogas (Fraunhofer IEE, 2018).

\section{THREE-STAGE PROCESSES}

Research on three-stage applications has proven, that the process conditions of $\mathrm{AD}$ can be further optimized. There exist different concepts for the separation of the process phases between the three stages. The first one is to separate the acetogens from the methanogens as they possess different nutritional requirements, resulting in an order of 1) hydrolysis/acidogenesis, 2) acetogenesis and 3) methanogenesis (Kim et al., 2006; Kim et al., 2008). As the interspecies hydrogen transfer is a critical factor in multi-stage $\mathrm{AD}$, the second concept is to rather split up hydrolysis and acidogenesis than to separate the acetogens and methanogens. This leads to the process sequence 1) hydrolysis, 2) acidogenesis, and 3) acetogenesis/methanogenesis, as described for several cases (Zhang et al., 2017; Chatterjee and Mazumder, 2019; Van et al., 2020). A review of Chatterjee and Mazumder (2019) in contrast, refers to the stage separation order 1) hydrolysis, 2) acidogenesis/ acetogenesis and 3) methanogenesis, mainly due to the adverse effect of mixing, which is required for the homogenization of waste in the first stage.

One of the first studies on three-stage AD originate from Kim et al. (2000). Under mesophilic conditions, FW was treated in a STR for hydrolysis/acidogenesis and two UASB for acidogenesis/ acetogenesis/methanogenesis. Production rates of up to $700 \mathrm{ml}$ biogas/(g VS) with a methane content of $72 \%$ were achieved. The enhanced degradation of three-stage $\mathrm{AD}$ was confirmed by COD reduction rates of over $90 \%$. Back in 2005, Salsali et al. showed that three-stage $\mathrm{AD}$ for the treatment of waste activated sludge can provide higher methane yields than two-stage digesters (Salsali et al., 2005). A maximum of over $650 \mathrm{ml}$ biogas/(g VS) were reached in their mesophilic application, operated with three STRs. A three-stage AD application with a focus on an enhanced hydrolysis in the first stage was compared to a single- and twostage process design by Zhang et al. (2017). Their FW-fed digester consisted of three chambers, responsible for hydrolysis, acidogenesis and methanogenesis in a sequential arrangement. The enhanced hydrolysis decreased the reduction of VS by half compared to the two-stage digester ( $44 \mathrm{vs} 83 \% \mathrm{w} / \mathrm{w}$ ). In addition, the methane yield of the three-stage application increased by up to $54 \%$; the methane content of the biogas rose to nearly $70 \%(\mathrm{v} /$ $\mathrm{v}$ ), assumingly due to an intensified hydrolysis compared to the two-stage process (Zhang et al., 2017). Similar results were described by Zhang et al. (2020). The authors used a threestage thermophilic reactor to treat a mixture of FW and horticultural waste. Methane yields were (with about $0.42 \mathrm{~L} / \mathrm{g}$ VS) $31-45 \%$ higher than those in one- and two-stage reactors. The reduction of VS (63\%) increased by over $60 \%$ compared to the single-stage system (Zhang et al., 2020). The anaerobic treatment of tofu whey wastewater (COD: $15.9 \mathrm{~g} / \mathrm{L}$ ) in a three- 
TABLE 2 | Examples for one-, two- and three-stage phase separation applications in anaerobic digestion.

\begin{tabular}{|c|c|c|c|c|c|c|c|c|}
\hline Feedstock & $\begin{array}{l}\text { Reactor } \\
\text { type } \\
\text { 1st, } \\
\text { 2nd, } \\
\text { 3rd }\end{array}$ & TS [\%] & $\begin{array}{c}\text { OLR } \\
\text { [g-VS/(L.d)] }\end{array}$ & HRT [d] & pH & $\begin{array}{c}\text { Biogas } \\
\text { yield }\left[\mathrm{ml}-\mathrm{CH}_{4} /\right. \\
(\mathrm{g}-\mathrm{VS})]\end{array}$ & Temp & Reference \\
\hline WAS & STR & 4.2 & - & 15 & 7 & 240 & mesophilic & Heng et al. (2021) \\
\hline Ensiled OFMSW & $\begin{array}{l}\text { Batch } \\
\text { reactor }\end{array}$ & $12-28$ & - & 25 & $6.0-8.2$ & 431 & mesophilic & $\begin{array}{l}\text { Castellón-Zelaya and } \\
\text { González-Martínez (2021) }\end{array}$ \\
\hline MSW and fly ash & STR & 9.72 & - & 45 & $7.2-7.5$ & $268-287$ & mesophilic & Markphan et al. (2020) \\
\hline OFMSW & STR & 1.75 & 1.35 & 25 & 7.94 & 404 & thermophilic & Schievano et al. (2012) \\
\hline Sewage sludge & STR & $4.0-5.2$ & $2.1-2.5$ & 15 & - & 260-306 & mesophilic & Salsali et al. (2005) \\
\hline Fruit waste & $\begin{array}{l}\text { micro } \\
\text { digester }\end{array}$ & 0.25 & - & 30 & $7.5-8.5$ & $610^{a}$ & mesophilic & $\begin{array}{l}\text { Chanakya and Shwetmala } \\
\text { (2017) }\end{array}$ \\
\hline \multirow[t]{2}{*}{ Sugar molasses } & $\begin{array}{l}\text { Packed } \\
\text { bed }\end{array}$ & - & 34 & $0.55-0.74$ & $4.5-5.2$ & $324^{b}$ & mesophilic & Detman et al. (2017) \\
\hline & UASB & & - & 6.71 & $6.5-7.6$ & & mesophilic & \\
\hline \multirow[t]{2}{*}{ Oily FW } & STR & 3.57 & 14.2 & 3 & 5.36 & 450 & thermophilic & Wu et al. (2015) \\
\hline & STR & 2 & 2.6 & 12 & 7.59 & & mesophilic & \\
\hline \multirow[t]{2}{*}{ MSW } & STR & 3.9 & 13 & 7.5 & $5.5-6$ & 540 & mesophilic & Li et al. (2017) \\
\hline & STR & - & 3.8 & 15 & - & & mesophilic & \\
\hline \multirow[t]{2}{*}{ Chicken manure } & glas vessel & 3.7 & 2.2 & 2 & $6.3-6.8$ & 554 & mesophilic & Dalkilıc and Ugurlu (2015) \\
\hline & glas vessel & & & 10 & $7.7-8$ & & thermophilic & \\
\hline \multirow[t]{2}{*}{$\begin{array}{l}\text { FW, grass, chicken } \\
\text { manure }\end{array}$} & $\begin{array}{l}\text { batch } \\
\text { reactor }\end{array}$ & 20 & 4 & 30 & & 113 & & Li W. et al. (2018) \\
\hline & $\begin{array}{l}\text { batch } \\
\text { reactor }\end{array}$ & & & & $6.6-7.5$ & & mesophilic & \\
\hline \multirow{2}{*}{$\begin{array}{l}\text { slaughterhouse blood } \\
\text { waste }\end{array}$} & tank reactor & 2.8 & 1.2 & 11.1 & $6-6.2$ & $384^{b}$ & mesophilic & Wang et al. (2018) \\
\hline & tank reactor & & $0.4-1$ & 24.2 & $7-7.5$ & & mesophilic & \\
\hline \multirow[t]{3}{*}{ Ethanol wastewater } & SBR & 3.17 & $15-21^{\mathrm{c}}$ & - & 5.5 & $686^{\mathrm{b}}$ & mesophilic & Jiraprasertwong et al. (2018) \\
\hline & SBR & - & - & & $6-7$ & & mesophilic & \\
\hline & SBR & - & - & & $7.2-7.5$ & & mesophilic & \\
\hline \multirow[t]{3}{*}{ Cassava wastewater } & UASB & - & $5-18^{c}$ & - & 5.5 & $328^{b}$ & mesophilic & Jiraprasertwong et al. (2019) \\
\hline & UASB & & - & & 6.8 & & mesophilic & \\
\hline & UASB & & - & & - & & mesophilic & \\
\hline \multirow[t]{3}{*}{ FW } & STR & 17.5 & $22-22.8$ & 2 & $5-5.5$ & $650-700$ & mesophilic (each & Kim et al. (2000) \\
\hline & UASB & 3 & $25-27.4$ & 2 & $5-5.5$ & & stage) & \\
\hline & UASB & 16 & $12-18.8$ & 12 & $7.6-7.9$ & & & \\
\hline \multirow[t]{3}{*}{ WAS } & STR & 4.6 & $2.13-2.53$ (each & 5 (each & 8 (each & $559-664$ & mesophilic (each & Salsali et al. (2005) \\
\hline & STR & 3.5 & stage) & stage) & stage) & & stage) & \\
\hline & STR & - & & & & & & \\
\hline
\end{tabular}

WAS, waste activated sludge; OFMSW, organic fraction of municipal solid waste; FW, food waste; MSW, municipal solid waste; STR, stirred tank reactor; UASB, upflow anaerobic sludge blanket; SBR, sequencing batch reactor.

${ }^{a}\left[\mathrm{ml}-\mathrm{CH}_{4} /(g-T S)\right]$.

${ }^{b}\left[\mathrm{ml}-\mathrm{CH}_{4} /(g-\mathrm{COD})\right]$.

${ }^{c}[g-C O D /(L \cdot d)]$

stage reactor was described by Rani et al. (2020). The authors used a system which consisted of three $10 \mathrm{~L}$ packed bed reactors. Due to the phase separation, which was indicated by the respective $\mathrm{pH}$-values, the system was able to resist hydraulic shock loads
(Rani et al., 2020). It was possible to maintain the biogas production rate $(20 \mathrm{~L} / \mathrm{d}$ ) as well as the $\mathrm{pH}$ value (around 5.0 in the first two reactors and around 7.0 in the third reactor) and the COD at the outflow after the organic load was increased 12 
fold for $1 \mathrm{~h}(0.33$ vs $4.0 \mathrm{~L} / \mathrm{h})$. The ratio of alkalinity to volatile SCCAs, which rose during the shock load, was reduced and stabilized within $8 \mathrm{~h}$ after the shock load. Superior process performance has also been reported for a three-stage anaerobic system using sequencing batch reactors, when compared to both single- and two-stage anaerobic processes treating several types of wastewaters (Jiraprasertwong et al., 2018). With an optimum COD loading rate of $18 \mathrm{~kg} /\left(\mathrm{m}^{3} \cdot \mathrm{d}\right)$, the process achieved $686 \mathrm{ml}$ $\mathrm{CH}_{4} / \mathrm{g}-\mathrm{COD}$, with an energy yield of $22.5 \mathrm{~kJ} / \mathrm{g}$-COD, and an overall COD removal of $92 \%$. The system performance has been related to the high microbial concentrations reached in the bioreactors, high alkalinity, and adequate $\mathrm{pH}$, with values of 5.5, 6.0-7.0, and 7.5 in the first, second, and third stages, respectively. Several typical residual resources contain lignocellulose. For the treatment of such feedstock, a separate hydrolytic stage, which relied on white rot fungi, was able to degrade lignin enzymatically (Wan and Li, 2012; Meegoda et al., 2018).

Further examples for $\mathrm{AD}$ applications with one, two and three stages and their respective process conditions are summarized in Table 2.

\section{EFFLUENT RECIRCULATION IN MULTI-STAGE AD}

Effluents from each stage can be recirculated and added to every tank in phase-separated AD. Thus, high degradation rates can be achieved, when e.g. incompletely degraded substances from the methanogenesis undergo hydrolysis twice, enhancing energy recovery up to $9 \%$ in two-stage systems (Chatterjee and Mazumder, 2019). Previous work has reported the dilution of high solid feedstocks and $\mathrm{pH}$ control, achieved by recirculating the alkaline effluent obtained in the second stage, as main benefits in two-stage AD (Van et al., 2020). In fact, this preserves nutrients and microorganisms in the system, allowing for the use of higher OLR, e.g. discussed by Menzel et al. (2020). By recirculating the liquid fraction of the AD effluent after solidliquid separation, a wash out of fluidized microorganisms to the next stage will decrease. Thereby, the retention times of the microbes is elongated, which also improves process stability and performance, as observed by Jiraprasertwong et al. (2018) in their three-stage AD system. Effluent recirculation can thus be used as a tool to stabilize and control AD processes, which is typically seen as a hurdle for their commercialization at largescale. Recent studies have proven that recirculation strategies are indeed beneficial to increase process stability and performance for e.g., in the digestion of toxic citrus wastes, while increasing methane yields by $79 \%$ (Wikandari et al., 2018). Qin et al. (2019) have also reported more stability in the longterm operation of a two-phase process with effluent recirculation for the $\mathrm{AD}$ of food and paper waste. The study suggested that hydrogen-producers were recirculated to the first-stage after proliferation in the second stage, which contributed to the production of $79 \mathrm{~L}-\mathrm{H}_{2} / \mathrm{kg}-\mathrm{VS}$ and $329 \mathrm{~L}-$ $\mathrm{CH}_{4} / \mathrm{kg}$-VS. Wang et al. (2020) have also demonstrated an improved hydrogen and methane production resulting from effluent recirculation in their two-stage $\mathrm{AD}$ experiments using FW combined with cow dung, while additionally reducing the amount of alkali addition for $\mathrm{pH}$ control in the hydrogenreactor. Paillet et al. (2021) reported that the performance of hydrogen production from anaerobic OFMSW degradation could be improved by $330 \%$, up to $17.2 \mathrm{ml} / \mathrm{g}-\mathrm{VS}$, when applying a strategy based on effluent recirculation and systematic heat shock treatment. Compared to a single-stage reactor, Ding et al. (2021) described an increased energy yield of $18 \%$ and a higher possible FW loading (up to $20 \%$ of the working volume), along with stable biogas production, in a FW-fed two-stage AD system with liquid recirculation from the methanogenic into the hydrolytic stage. The recirculation of the effluent from the second reactor also led to a higher robustness of the system against side effects through high OLR (e.g. acidification) compared to the single-stage application. Moreover, methane yields of nearly $400 \mathrm{ml} / \mathrm{g}$-VS, that is over $90 \%$ of the methane production potential, were reported. Recirculation of the liquid phase can stabilize the microbial consortium and adds another possibility for process control. $\mathrm{Wu}$ et al. (2015) investigated the performance of two temperature-phased (thermophilic-mesophilic) double-STR digesters for the treatment of FW and compared it to a mesophilic single-stage application. In the two-stage digester without recirculation, the processes of hydrolysis and acidogenesis were inhibited by a $\mathrm{pH}$ drop below 4.0 in the first stage. Thus, the results for the methane production were very similar to the mono-digester, around 440 to $450 \mathrm{ml}-\mathrm{CH}_{4} /$ ( $g$-VS). The methane ratio in the produced biogas from the second digester was 61\% (Wu et al., 2015). The two-stage AD application with recirculation from the second into the first stage achieved to keep the $\mathrm{pH}$-value in the first digester at an optimal level of 5.0-5.5. In consequence, the microorganisms in the first digester produced biogas with a hydrogen share of $30 \%$ $(\mathrm{v} / \mathrm{v})$. The portion of methane in the biogas rose to $70 \%(\mathrm{v} / \mathrm{v})$. The particulate COD was reduced from $66.7 \%$ in the substrate to $10.3 \%(\mathrm{w} / \mathrm{w})$ in the effluent. In comparison, in the single-stage digester and the two-stage $\mathrm{AD}$ application without recirculation, the COD remained at $14.6 \%(\mathrm{w} / \mathrm{w})$.

Effluent recirculation in two-stage $\mathrm{AD}$ processes, however, must be carefully monitored and controlled, as methane production may be favored at a $\mathrm{pH}$-value that is higher than 6.0, hindering biohydrogen production (Micolucci and Uellendhal, 2018). This issue is avoided in three-stage AD systems with separated hydrolysis and acidogenesis, as the recirculation of methanogenic sludge into the first stage does not interfere with hydrogen synthesis in the acidogenic reactor (Jiraprasertwong et al., 2018).

\section{MONITORING AND CONTROL}

A reliable monitoring and control system is a pre-requisite for phase separation in AD. A suitable monitoring system is required to orchestrate the exchange of the gas, and in particular the liquid phase in between the stages to prevent cell starvation or product inhibition. 
Sensors for AD need a resistance against chemical and physical conditions like low $\mathrm{pH}$-values and an undefined multiplecomponent matrix in the broth (Bockisch et al., 2019). Naturally, an important process parameter for $\mathrm{AD}$ is the $\mathrm{pH}$ value. The response time of the system's $\mathrm{pH}$-value to changing conditions inside is not by all means very fast due to the buffer capacity of the broth (Li et al., 2014). An accumulation of acids inside a tank does not necessarily mean an immediate decrease of the $\mathrm{pH}$-value. Any drop in the $\mathrm{pH}$-value exhibits severe imbalances, which cannot be rapidly counteracted and typically need several days or even weeks to recover (Pfeiffer et al., 2020). In that case, the OLR has to be decreased significantly, even the addition of anti-foam agents might be needed due to increased cell lysis rates and protein excretion (Moeller and Zehnsdorf, 2016). Controlling the pH-value, however, is the most suitable tool for separating the different groups of microorganisms between the reactors of multi-stage $\mathrm{AD}$. At a low $\mathrm{pH}$-value of between 5.0 and 6.0 , the presence of methanogens in the acidogenic phase is prevented. The $\mathrm{pH}$-value can be measured with on line monitoring methods like classical voltametric $\mathrm{pH}$ electrodes $(\mathrm{AgCl})$, fluorescence based sensors or ion selective field effect transistors (Jimenez-Jorquera et al., 2010; Bockisch et al., 2014; Janzen et al., 2015). Fluctuations of the pHvalue caused by an organic overload of the $\mathrm{AD}$ system can be corrected by reducing the substrate feed. Acidified digesters can be treated additionally with sodium bicarbonate in a bypass or between the stages of multi-stage $\mathrm{AD}$ to rise the $\mathrm{pH}$-value (Burgstaler et al., 2010).

For all $\mathrm{AD}$ applications, especially for FW-treating digesters, the amount of produced SCCAs is a proper parameter to observe the process functionality (Pfeiffer et al., 2020). An adequate amount of the effluent from the acidogenesis needs to be transferred to the second (or third) stage in order to prevent starvation in the methanogenic stage without the risk of its acidification. SCCAs can be monitored on- and off line with near or mid-wavelength infrared spectroscopy sensors (Falk et al., 2015; Nespeca et al., 2017). Infrared spectroscopy (Nespeca et al., 2017) or gas chromatography for the detection of volatile compounds (Zheng et al., 2020) has proven to be a suitable strategy for identifying concentration changes of acids in a short time scale (Björnsson et al., 2001), however this is rarely applied in practice so far.

Alkalinity is also considered as an early-warning indicator that can effectively predict disturbances in $\mathrm{AD}$ processes. Several studies have demonstrated that enhanced SCCA production could be obtained from sewage sludge under alkaline conditions, typically using $\mathrm{NaOH}$ to maintain $\mathrm{pH}$ values around 10 (Kurahashi et al., 2017; Liu et al., 2018). Controlled alkalinity at a $\mathrm{pH}$ in the range of between 10 and 11 during the $\mathrm{AD}$ of sewage sludge in a full-scale reactor $\left(30 \mathrm{~m}^{3}\right)$ inhibited methane production, while enhancing SCCA accumulation, particularly acetic acid which accounted for $58 \%(w / w)$ of the total SCCAs (Liu et al., 2018). A thorough review about process stability for $\mathrm{AD}$ of $\mathrm{FW}$ has suggested that a ratio of intermediate to partial alkalinity (IA/PA) lower or equal to 0.3 should be used, along with total alkalinity (TA) concentrations of between 13 and $15 \mathrm{~g} / \mathrm{L}$ (Li et al., 2018). Despite the proposed thresholds, these depend on substrate quality and the type of operation, and are less reliable under variable feedstock or operating conditions ( $\mathrm{Wu}$ et al., 2019).

Cell polarizability measurements can provide a value that reflects the metabolic activity of cells that is related to cell physiology. This is especially helpful if different consortia exist in multiple stages while the measurement of intermediates, and thus the production rates, is not easily feasible or cell stress that usually leads to a reduction of the polarizability, shall be prevented quickly. This can be starvation due to a lack of nutrient supply or an oversupply of nutrients. Frequencydispersed anisotropic polarizability (FDAP) can be used as an at-line control to evaluate cell viability and activity in each stage. Such electrooptical measurements have been successfully used to monitor DF using mixed cultures (Gómez-Camacho et al., 2020), which exposes a different metabolic activity on the dependence of acid accumulation. The same study also revealed the suitability of flow cytometry for DF cultures, in which a typical live-dead staining can be conducted, which is otherwise difficult in cultures of one-stage $\mathrm{AD}$, probably due to agglomerate formation between acidogens and methanogens.

Ammonia acts as an inhibitor for specific enzymatic reactions. It has been shown previously that biogas plants suffer from microbial inhibition and methane losses when using $\mathrm{N}$-rich substrates (Morozova et al., 2020). While concentrations above $200 \mathrm{mg} / \mathrm{L}$ are considered to hinder AD significantly, according to Chen et al. (2008), lower amounts are beneficial for stabilizing AD processes, by buffering the system (Nsair et al., 2020). Ammonia concentrations of $14 \mathrm{mg} / \mathrm{L}$ can already have an impact on methane production, as described by Nsair et al. (2020). Therefore, in multi-stage AD applications, the monitoring of ammonia concentrations has a particular importance for the methanogenic stage. Ammonia can be measured with potentiometric sensors, electronic tongues or luminescent ammonia sensors (Nery and Kubota, 2016; Urriza-Arsuaga et al., 2019). A study comparing off line and on line measurements concluded that the $\mathrm{NH}_{4}$ electrode had high accuracy, but was strongly affected by sodium and potassium, so that it was not of an equal accuracy (Zhou and Boyd, 2016). The performance of $\mathrm{AD}$ can also benefit from a microbial adaptation, e.g. through a gradually $\mathrm{N}$-increasing feeding rate, in which the viability and activity of the microbial community is investigated (Morozova et al., 2020). An issue remains for measurements at the typically high concentrations above $50 \mathrm{mg} / \mathrm{L}$, which hinders often on line applications as it is not easily feasible to dilute the broth in an automatic manor.

In order to use the hydrogenotrophic methane production pathway, methanogenic archaea are dependent on dissolved hydrogen in the liquid phase of an $\mathrm{AD}$ application. The hydrogen solubility in water is low. At $25^{\circ} \mathrm{C}$ and a pressure of 1 bar, hydrogen saturated water contains $1.6 \mathrm{mg}$ hydrogen/L (Kaye and Laby, 1992). Nevertheless, an accumulation of hydrogen during $\mathrm{AD}$ can inhibit the growth of certain acidogenic bacteria (e.g. Clostridium). While the threshold depends on the microbial consortia, hydrogen partial pressures above $10^{-5}$ to $10^{-3}$ bar are described as having negative effects, especially on butyrate and propionate degradation (Lowe et al., 
1993; Mutungwazi et al., 2021). In the worst case, this can lead to a collapse of the $\mathrm{AD}$ system and the biogas production through acidification (Huck et al., 2013).

In multi-stage $\mathrm{AD}$, the interspecies-hydrogen transfer between acidogens and methanogens is interrupted due to their spatial separation. The phase-transfer from gas to liquid can thus act as the bottleneck of methanation (Díaz et al., 2020). Monitoring of the process stability simply by observing the gas phase may result in problems like reactor overloads, as the reaction to system changes in the headspace tends to be slow compared to the response in the liquid phase (Björnsson et al., 2000). Björnsson et al. (2001) showed, that the dissolved hydrogen concentration reacts faster to changes in OLR or other system fluctuations, for example the accumulation of SCCAs. In their experiments, the authors used an on-line Teflon membrane for sampling, combined with a semiconductor sensor, which is highly hydrogen specific (Björnsson et al., 2001).

Acetogenic bacteria are highly dependent on the hydrogen uptake by the archaea, as the accumulation of dissolved hydrogen leads the inhibition of their degradation of SSCA like butyrate and propionate (Harper and Pohland, 1986). In consequence, these acids can be enriched and cause further system instabilities. It was shown that ethanol accumulated up to $0.08 \mathrm{~g} / \mathrm{L}$ under a hydrogen headspace pressure of 2 bar during anaerobic digestion. The profile of acids was partially altered (Sarkar et al., 2017). This example demonstrates that hydrogen plays a crucial regulatory role in acidogenesis and acetogenesis; a partial pressure of hydrogen below $10^{-4}$ bar is required to maintain the thermodynamical feasibility of the acid synthesis (Pavlostathis, 2011). Thus, the monitoring of the dissolved hydrogen shows, if the different groups of microorganisms act at equilibrium (Björnsson et al., 2001). The monitoring of dissolved hydrogen is typically coupled to the use of membranes in order to increase the hydrogen selectivity of a measurement unit. These membranes tend to be overgrown by microbial communities and their biofilms in AD applications. Researchers at the KurtSchwabe-Institute (Meinsberg, Germany) are developing a new approach for the on-line measurement of dissolved hydrogen based on the potentiostatic coulometry. The system relies on a gas-liquid extraction without membranes (Zosel et al., 2011). Optimization work for the application in $\mathrm{AD}$ is ongoing.

\section{BIOLOGICAL METHANATION OF HYDROGEN}

Demand-oriented energy production is a main issue in a sustainable society, which relies on fluctuating energy resources. During the ongoing transformation of the energy supply systems, a temporary surplus or shortage of electrical power occurs with the necessary expansion of renewable resources like wind and solar power (Sensfuss and Pfluger, 2014; Peters et al., 2018). For instance, feed-in management measures led to the curtailment of 5.4 TWh from renewables in Germany in 2018, 97\% of it originated from wind plants (Bundesnetzagentur, 2019). Energy curtailment created costs of 1.5 billion Euro to Germany's electricity consumers in 2017 (International Energy Agency, 2020). Flexible biogas production has the potential to partly buffer this residual load in rural areas up to a certain degree (Lecker et al., 2017). In recent years, the concept of power-to-gas has gained a broad interest (Peters et al., 2018). Surpluses of electrical energy from renewable sources can be used to produce hydrogen from water by electrolysis. In combination with carbon dioxide, this hydrogen can react chemically to methane through the Sabatier reaction (Lecker et al., 2017; Rachbauer et al., 2017).

$$
\mathrm{CO}_{2}+4 \mathrm{H}_{2} \rightarrow \mathrm{CH}_{4}+2 \mathrm{H}_{2} \mathrm{O}
$$

This process is called chemical methanation. To store the chemical energy as gas withing the gas distribution grid is much easier compared to storing electricity. The German gas grid, for example, can store up to 260 TWh of energy on its own (Lecker et al., 2017).

In biogas reactors, hydrogenotrophic methanogens (archaea) like methanococcales or methanobacterium convert hydrogen into methane through the Sabatier reaction (Bassani et al., 2015; Rachbauer et al., 2017). The hydrogen for biological methanation originate from the electrolysis of water, the required carbon dioxide can be taken from the AD process (Peters et al., 2018). Thus, the concept is suited for a multi-stage $\mathrm{AD}$ : the first stage provides the necessary carbon dioxide for the methanation and simultaneously provide SCCAs as a carbon source for archaea. With the lack of intermediates from fermentative bacteria, a single-stage methanation would have to rely on an additional supply with organic carbon and different trace elements.

Through the addition of hydrogen to $\mathrm{AD}$ applications, hydrogenotrophic methanogenesis is amplified and a shift in consortia of methanogenic archaea is observable (Rachbauer et al., 2017; Okoro-Shekwaga et al., 2019). A higher quantity of hydrogenotrophic methanogens leads to a higher quality of the biogas due to the exhaustion of the carbon dioxide, e.g. originating from the previous $\mathrm{AD}$ processes, during methanogenesis. Therefore, a utilization of external hydrogen in biogas plants can decrease the costs for the enrichment of biogas, if used as biomethane (Lecker et al., 2017).

Hydrogenotrophic methanogenesis in multi-stage AD with addition of hydrogen has been investigated by several researchers. Bassani et al. (2015) described that hydrogen addition to a twostage AD-reactor (STR) fed with cattle manure increased the content of methane in the biogas from $70 \%$ to nearly $90 \%(\mathrm{v} / \mathrm{v})$ under mesophilic conditions through hydrogen inflow. The HRT was 25 days in the first and 33 days in the second reactor, with a total OLR of $0.6 \mathrm{~g}-\mathrm{VS} /(\mathrm{L} \cdot \mathrm{d})$. The hydrogen was added to the second reactor through a diffuser at a rate of $192 \mathrm{ml} /(\mathrm{L} \cdot \mathrm{d})$, to meet the stoichiometric needs for methanation (four moles of hydrogen per mole of carbon dioxide). Similar results were achieved by Luo et al. (2012). The authors demonstrated that the methane production rate of a cattle manure $(3 \%(\mathrm{w} / \mathrm{w})$ of TS, of which $2.6 \% \mathrm{VS}$ ) increased more than $20 \%$ due to the continuous addition of hydrogen. According to Peters et al. (2018), the methane fraction in the biogas can achieve up to $95 \%$ through hydrogenotrophic methanogenesis. Km values of anaerobic cell suspensions are in the range of between 5 and $10 \mu \mathrm{M}$ (Robinson and Tiedje, 1982). The addition of hydrogen to $\mathrm{AD}$ applications results in a rising partial pressure, which can 
even lead to inhibition as described in a previous section. If it is converted fast enough, it creates no change in substrate consumption though as shown by Luo and Angelidaki (2013). The possibilities of biogas upgrading by pulse hydrogen addition to $\mathrm{AD}$ fed with straw and sludge from a biogas plant was investigated by Agneessens et al. (2017). An OLR of $0.77 \mathrm{~g}$ $\mathrm{VS} /(\mathrm{L} \cdot \mathrm{d})$ and a HRT of 20 days were chosen as process conditions. The experiments showed a fast adaption and hydrogen assimilation of the microbial community, an increase of hydrogenotrophic methanogens as Methanobacterium was detected. The methane production (up to $0.44 \mathrm{~L} /(\mathrm{L} \cdot \mathrm{d})$ ) was reduced at a carbon dioxide gas concentration below 12\% (v/v) (Agneessens et al., 2017), which shows the importance to maintain a sufficient availability to restrict it to become rate limiting.

Methanobacterium was one of the prevalent archaea found by Li et al. (2020) on the conversion of hydrogen to methane in a two-stage anaerobic digester fed with rice-straw. It was possible to increase the methane yield (by 45\%) and the methane share in the biogas (by 101\%) through addition of hydrogen to a STR - upflow reactor combination ( $\mathrm{Li}$ et al., 2020). The concept of hydrogen addition to upgrade the produced biogas was also investigated in a two-stage thermophilic reactor (STR and upflow reactor) digesting cattle manure and potato-starch by Corbellini et al. (2018). The hydrogen was injected in the first reactor and channeled to the second one, together with the offgas. $98 \%$ of the hydrogen was metabolized into methane.

Within the large group of methanogenic archaea, countless numbers of species exist. Some of these species are especially persistent against the stress caused by the process conditions inside of an $\mathrm{AD}$ reactor or the chemical substances inflowing with the feed. The concept of enriching exactly these microorganisms with bioaugmentation is used since nearly $20 \mathrm{yr}$ (Nzila, 2017). The concept is especially suitable for multi-stage $\mathrm{AD}$, where the different organism groups can be augmented more individually. It was observed by Ács et al. (2019), as they changed the conditions inside a mesophilic lab-scale reactor, inoculated with the effluent of an industrial biogas plant (for pig manure and plant silage), to those of a power-to-methane system, by sole hydrogen feeding. The diversity of the archaea community was significantly reduced, while Methanobacterium remained the predominant genus (Ács et al., 2019). Zhang et al. (2018) described an example of how to use syntrophic relationships of anaerobic digesters in combination with bioaugmentation. They added exoelectrogenic Geobacter sulfurreducens to a batch culture of methanogens. Methanosaetaceae and Methanobacteriaceae benefited strongly from the augmentation, as they occurred in direct vicinity of the new species. With this new bioaugmentation strategy, the methane production rate was increased by nearly $80 \%$. A rearrangement of the methanogenic consortium inside an $\mathrm{AD}$ application is especially helpful for the treatment of nutrientpoor substrates, or those which have a high amount of inhibitors like ammonia, as seen by the experimental results from Li Y. et al. (2018) and Fotidis et al. (2017).

An alternative to the direct addition of hydrogen to full $\mathrm{AD}$ is a single methanogenic stage or bio-electrochemical methanogenesis, which could benefit from carbon dioxide supply of other AD stages, but would be operated separately from the broth streams. The utilization of power-to-gas has also been examined for bio-electro-methanogenesis with pure or mixed methanogenic cultures, combining electrochemical operation with microbial conversion to produce methane from carbon dioxide. Cathodes inside the bioreactors act as electron donators for the methanogenic reduction of carbon dioxide or as in-situ hydrogen producers (Geppert et al., 2019; Kracke et al., 2019). In-situ hydrogen production in bio-electrochemical methanogenesis offer a flexibilization of energy production through power-to-gas applications, as they can be used with single-stage, pure methanogenic species in defined cultures and without external hydrogen supply. Kracke et al. (2020) investigated the power-to-gas electromethanogenesis of Methanococcus maripaludis in stirred bio-electrochemical reactors. Carbon dioxide for the biological methanation was continuously added. Volumetric methane production rates of nearly $1.4 \mathrm{~L} /(\mathrm{L} \cdot \mathrm{d})$ were achieved. The methanogens, that were exposed to cathodes showed slightly higher metabolization efficiency than a control group, which was supplied with external hydrogen. The efficiency of Methanococcus maripaludis in terms of electro-methanogenesis was confirmed by Mayer et al. (2019), who compared the electrosynthesis of methane of different archaea strains in a fed-batch, two-chamber pilot-scale reactor (H-cell), and by Enzmann et al. (2019), using carbon dioxide fed bubble columns with carbon layer cathodes. Kobayashi et al. (2017) used a thermophilic $\left(55^{\circ} \mathrm{C}\right)$, high-pressure system with a mixed culture of methanogens for the bioelectrochemical synthesis of methane. The archaea in the system were dominated by Methanothermobacter (Kobayashi et al., 2017). At even higher temperatures $\left(60^{\circ} \mathrm{C}\right)$, but with atmospheric pressure, Song et al. (2019) did similar experiments with a mixed culture of methanogens.

The overall efficiency of a process nexus (electrolysis, methanation and conversion into usable energy) is barely above $50 \%$, depending on the pressure and the temperature (Bernacchi et al., 2014). Nevertheless, the conversion of hydrogen into methane represents a promising technology for the prospective increase of energy supply from fluctuating sources. While this concept can be implemented directly into existing digestion processes, research results exist only from pilot scale applications yet and therefore need further investigation on the large scale (Lecker et al., 2017; Theuerl et al., 2019).

\section{MODELLING OF MULTI-STAGE AD PROCESSES}

Mathematical models are an important tool to understand and predict the degradation processes in AD. They are especially helpful for designing and operating multi-stage reactor concepts, as they estimate the flow rates between and feeding rates of the individual stages. Naturally, first mechanistic models were obviously established for single-stage $\mathrm{AD}$ processes. Blumensaat and Keller (2005) adapted the "Anaerobic Digestion Model No. 1 (ADM1)" to a two-stage AD process. The authors were able to predict the process performances of 
both stages individually. Muha et al. (2013), simulated the share of reactions in a leach bed reactor and an anaerobic filter. According to the model, all steps of $\mathrm{AD}$ took place in both reactors except for the hydrolysis: about $40 \%$ of the acidogenesis and nearly $75 \%$ of the methanogenesis occurred in the second stage. Vega De Lille et al. (2016) were able to predict the COD course from domestic wastewater in a two-stage $\mathrm{AD}$ system, consisting of a sequencing batch reactor and a fixed bed reactor. The authors used an adjusted ADM1, which showed good results for the degradation of varying feedstock. Kamyab and Zilouei (2021) simulated the biogas production from a two-stage mixed UASB reactor for the treatment of baker's yeast wastewater. It predicted, that the efficiency of the COD removal rises from 11 to $36 \%$ with an increased input concentration between 1.5 and $4.1 \mathrm{mg}-\mathrm{COD} / \mathrm{cm}^{3}$. Simultaneously, the methane production rate decreases from $1.2 \mathrm{~L} / \mathrm{g}-\mathrm{COD}$ at $1.5 \mathrm{mg}-\mathrm{COD} / \mathrm{cm}^{3}$ to almost zero at $4.1 \mathrm{mg}-\mathrm{COD} / \mathrm{cm}^{3}$. Bayen and Gajardo (2019) used the anaerobic digestion model AM2 for simulating biogas production it in a two-stage system consisting of a separate acidogenic and methanogenic stage. The model expressed the optimal flow rates within the system, e.g. for the treatment of a substrate with a high release of SCCAs.

Mathematical models for AD are often developed for a certain scope of application. Therefore it can be useful to adapt models from a different application for one or all stages of $\mathrm{AD}$, as described by Postawa (2018). He used a model originally designed for high pressure $\mathrm{AD}$, to predict the biogas production in a temperature phased two-stage $\mathrm{AD}$ and compared the results with literature data. While not fully optimised, the model predicted the biogas production well for time periods of 40 days in $\mathrm{AD}$. The recent results from the modelling of multi-stage $\mathrm{AD}$ processes show that stage separation becomes predictable. It might be even easier to simulate separate stages as the number of parallel reactions and influencing factors is reduced. If sufficient data under dynamic operation is available, either the production dynamics can be predicted or process disturbances can be identified with suitable monitoring tools. On a system level, the potential yields and value generation can be simulated.

\section{ECONOMIC COMPETITIVENESS AND ALTERNATIVE PRODUCTS}

Due to the higher investment and operational costs, and although promising as described previously, multi-stage digesters cannot compete economically for all types of feedstock. The investment costs for single- and two-stage biogas plants with a capacity of $100 \mathrm{~kW}$ have been estimated as $7000 € / \mathrm{kW}$ (Carlini et al., 2017) and $7400 € / \mathrm{kW}$ (Renda et al., 2016), respectively. Organic waste residues with a dry matter content below $3 \%$ like sewage sludge exhibit similar methane yields $\left(0.5 \mathrm{~L} /\left(\mathrm{L}_{\text {digestate }} \cdot \mathrm{d}\right)\right.$ when treated either in single-stage AD (STR) or two-stage processes (Schievano et al., 2012; Van et al., 2020). For the transfer between the stages of $\mathrm{AD}$, a sufficient mixing is a premise. Thus, multi-stage $\mathrm{AD}$ is typically operated with STRs. Feedstock with a high TS-content $(>15-20 \%)$ is difficult to apply in these reactors due to the high viscosity (Van et al., 2020). According to this study, great amounts of water and energy as well as long HRT are needed to treat such feedstock in two-stage digesters. Therefore, dry single-stage digesters are recommended in this case.

Beside the benefits for biogas production, phase separation in $\mathrm{AD}$ allows the recovery of value-added side products from some of the stages, e.g. from DF. Two-stage AD processes for the combined production of biohydrogen and biomethane from organic wastes can yield a biohythane gas containing $10-15 \%$ $\mathrm{H}_{2}, 50-55 \% \mathrm{CH}_{4}$, and $30-40 \% \mathrm{CO}_{2}$. The upgrade of the SCCAenriched liquid effluent generated in the first stage can lead to higher energy recovery and higher degradation efficiency than in traditional biogas production processes (O-Thong, 2018). Li et al. (2020) tested a semi-continuous two-stage AD system for biohythane production from cornstalk. The hydrogen production in the first-stage reached $25 \mathrm{ml} / \mathrm{g}$-TS, the hydrogen content in the biohythane gas was $18.47 \%$. In the second stage UASB, a methane yield of $95 \mathrm{ml} / \mathrm{g}$-TS was additionally achieved by using the liquid effluent generated in the first stage. Ghimire et al. (2020) investigated the role of temperature in a two-stage $\mathrm{DF}$ and $\mathrm{AD}$ process using $\mathrm{FW}$, and observed that mesophilic $\left(34^{\circ} \mathrm{C}\right) \mathrm{DF}$ provided a hydrogen yield of $53.5 \mathrm{ml} \mathrm{H}_{2} / \mathrm{g}$-VS, while thermophilic conditions $\left(55^{\circ} \mathrm{C}\right)$ favored methane yields in $\mathrm{AD}$, achieving $307.5 \mathrm{ml} \mathrm{CH}_{4} / \mathrm{g}-\mathrm{VS}$. Yan et al. (2020) assessed the performance of a two-stage system using leach bed reactors for the AD of several types of FW, and achieved a hydrogen production of $61 \mathrm{ml} / \mathrm{g}$-VS. By applying the produced leachate and acidogenic off-gas in the second stage, the authors reached a methane production of $420 \mathrm{ml} / \mathrm{g}-\mathrm{VS}$. Chen et al. (2021) used a temperature phased AD of rice straw and pig manure for biohythane production. In a mesophilic-thermophilic reactor concept, up to $16.7 \mathrm{ml}-\mathrm{H}_{2} /$

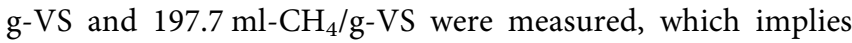
a ratio of $1 \mathrm{ml} \mathrm{H}_{2}$ per $12 \mathrm{ml} \mathrm{CH}_{4}$.

Based on the DF of several biodegradable wastes, it is estimated that two-thirds of the carbon input can be fermented into SCCAs such as acetic, propionic, butyric, isovaleric, valeric and caproic acid, among others (Slezak et al., 2017). Although extensive reviews exist on the topic, SCCAs production via $\mathrm{AD}$ is sensitive to several operational factors, namely feedstock, $\mathrm{pH}$-value, temperature, organic loading rate, alkalinity, and retention time, respectively, which typically depict a synergetic effect on the microbial consortia (Atasoy et al., 2018). Before SCCAs gain an economic value during $\mathrm{AD}$, they have to be concentrated and separated from the effluent (Kleerebezem et al., 2015). Gioannis et al. (2017) described the production of SCCAs in a single- and two-stage FW-fed STR. SCCAs concentrations of $5 \mathrm{~g} / \mathrm{L}$ were detected in the acidogenesis stage. Bioaugmentation has been successfully applied to enhance SCCAs production, increasing butyric and caproic acid yields by up to $300 \%$ with Clostridia, Sphingobacteriales, Desulfobacteraceae and Bacillus species (Reddy et al., 2018). Further investigation is required to maximize acid concentration while keeping the microbial consortia vital and eventually combine the concomitant biomass growth with the enrichment of species that have a high value as fertilizer, e.g. for soil recovery or as biofungicide producers like Bacillus sp. 


\section{CONCLUSION}

Phase separation in $\mathrm{AD}$ provides a great potential for the flexibilization of $\mathrm{AD}$ applications, which is beneficial for a demand-driven biogas production. With more research on upscaling, this approach is likely to be become applicable while using similar infrastructure as conventional AD processes.

Monitoring concepts coupled with dynamic effluent recirculation as also discussed in this work, allow for an increasing system robustness and stability. A robust and stable system also facilitates the use of feeding strategies with alternating feedstock, making it possible to integrate $\mathrm{AD}$ into regional material cycles. Strategies such as bioaugmentation help the adaptation of microbial communities that are most suitable for the conditions and requirements of the specific $\mathrm{AD}$ application.

Finally, additional benefits from the separation of SCCAs between stages of a multi-phase $\mathrm{AD}$ can couple biomass energy and material use. As one example, among others, the use of SCCAs as feed for the production of long-chain polyunsaturated fatty acids in subsequent microalgae monocultivation processes shall be mentioned (Chalima et al., 2020; Patel et al., 2021). They have a high value in nutrition and serve as a replacement of fish oil and fish meal. Such a process can, beside the value addition, represent a more sustainable production of these compounds for food and feed application (Bartek et al.,

\section{REFERENCES}

Ács, N., Szuhaj, M., Wirth, R., Bagi, Z., Maróti, G., Rákhely, G., et al. (2019). Microbial Community Rearrangements in Power-To-Biomethane Reactors Employing Mesophilic Biogas Digestate. Front. Energ. Res. 7, 132. doi:10.3389/fenrg.2019.00132

Agneessens, L. M., Ottosen, L. D. M., Voigt, N. V., Nielsen, J. L., de Jonge, N., Fischer, C. H., et al. (2017). In-situ Biogas Upgrading with Pulse H 2 Additions: The Relevance of Methanogen Adaption and Inorganic Carbon Level. Bioresour. Technol. 233, 256-263. doi:10.1016/j.biortech.2017.02.016

Ariunbaatar, J., Panico, A., Esposito, G., Pirozzi, F., and Lens, P. N. L. (2014). Pretreatment Methods to Enhance Anaerobic Digestion of Organic Solid Waste. Appl. Energ. 123, 143-156. doi:10.1016/j.apenergy.2014.02.035

Atasoy, M., Owusu-Agyeman, I., Plaza, E., and Cetecioglu, Z. (2018). Bio-based Volatile Fatty Acid Production and Recovery from Waste Streams: Current Status and Future Challenges. Bioresour. Technol. 268, 773-786. doi:10.1016/ j.biortech.2018.07.042

Bartek, L., Strid, I., Henryson, K., Junne, S., Rasi, S., and Eriksson, M. (2021). Life Cycle Assessment of Fish Oil Substitute Produced by Microalgae Using Food Waste. Sustainable Prod. Consumption 27, 2002-2021. doi:10.1016/ j.spc.2021.04.033

Bassani, I., Kougias, P. G., Treu, L., and Angelidaki, I. (2015). Biogas Upgrading via Hydrogenotrophic Methanogenesis in Two-Stage Continuous Stirred Tank Reactors at Mesophilic and Thermophilic Conditions. Environ. Sci. Technol. 49, 12585-12593. doi:10.1021/acs.est.5b03451

Bayen, T., and Gajardo, P. (2019). On the Steady State Optimization of the Biogas Production in a Two-Stage Anaerobic Digestion Model. J. Math. Biol. 78, 1067-1087. doi:10.1007/s00285-018-1301-3

Bernacchi, S., Weissgram, M., Weissgram, M., Wukovits, W., and Herwig, C. (2014). Process Efficiency Simulation for Key Process Parameters in Biological Methanogenesis. AIMS Bioeng. 1, 53-71. doi:10.3934/bioeng.2014.1.53

Bischofsberger, W. (2005). Anaerobic Technology [in German]. Berlin: Springer.

Björnsson, L., Murto, M., and Mattiasson, B. (2000). Evaluation of Parameters for Monitoring an Anaerobic Co-digestion Process. Appl. Microbiol. Biotechnol. 54, 844-849. doi:10.1007/s002530000471
2021). Nevertheless, research and development to increase the cost-efficiency of coupled systems and reduce efforts for separation is a pre-requisite so that such process combinations will be applied in industrial scale. Finally, data for technoeconomic and sustainability assessments are required to identify suitable feedstock-product combinations within the manyfold options that a multi-stage $\mathrm{AD}$ theoretically offers to its users.

\section{AUTHOR CONTRIBUTIONS}

EJ collected data, performed literature research, and wrote the main body of the manuscript. JP supported data collection and manuscript preparation and review. PN supported supervision of the manuscript preparation and review. SJ supported data collection, supervised manuscript preparation and review.

\section{FUNDING}

The authors acknowledge funding of the German Federal Ministry for Economics within the framework program Biomass energy use, grant no. 03EI5409A.

Björnsson, L., Murto, M., Jantsch, T. G., and Mattiasson, B. (2001). Evaluation of New Methods for the Monitoring of Alkalinity, Dissolved Hydrogen and the Microbial Community in Anaerobic Digestion. Water Res. 35, 2833-2840. doi:10.1016/S0043-1354(00)00585-6

Blank, A., and Hoffmann, E. (2011). Upgrading of a Co-digestion Plant by Implementation of a Hydrolysis Stage. Waste Manag. Res. 29, 1145-1152. doi:10.1177/0734242X11423954

Blumensaat, F., and Keller, J. (2005). Modelling of Two-Stage Anaerobic Digestion Using the IWA Anaerobic Digestion Model No. 1 (ADM1). Water Res. 39, 171-183. doi:10.1016/j.watres.2004.07.024

Bockisch, A., Biering, J., Päßler, S., Vonau, W., Junne, S., and Neubauer, P. (2014). In Situ Investigation of the Liquid Phase in Industrial Yeast Fermentations with Mobile Multiparameter Sensors. Chem. Ingenieur Technik 86, 1582. doi:10.1002/cite.201450231

Bockisch, A., Kielhorn, E., Neubauer, P., and Junne, S. (2019). Process Analytical Technologies to Monitor the Liquid Phase of Anaerobic Cultures. Process Biochem. 76, 1-10. doi:10.1016/j.procbio.2018.10.005

Borja, R. (2011). "Biogas Production," in Comprehensive Biotechnology. Editors M. Butler and M. Moo-Young (Saint Louis, MO: Elsevier), 785-798. doi:10.1016/b978-0-08-088504-9.00126-4

Bundesnetzagentur (2019). Monitoring Report 2019 - Key Findings and Summary. Bonn.

Burgstaler, J., Blumenthal, J., Wiedow, D., Godlinski, F., and Kanswohl, N. (2010). Possibilities to Regulate the $\mathrm{pH}$ Value of Acidified Biogas Fermenters and the Effects on the Biogas Yield. Available at: http://nbn-resolving.de/urn:nbn:de:gbv: 253-201012-dn047464-1 (Accessed March 4, 2021).

Carlini, M., Mosconi, E., Castellucci, S., Villarini, M., and Colantoni, A. (2017). An Economical Evaluation of Anaerobic Digestion Plants Fed with Organic AgroIndustrial Waste. Energies 10, 1165. doi:10.3390/en10081165

Castellano-Hinojosa, A., Armato, C., Pozo, C., González-Martínez, A., and González-López, J. (2018). New Concepts in Anaerobic Digestion Processes: Recent Advances and Biological Aspects. Appl. Microbiol. Biotechnol. 102, 5065-5076. doi:10.1007/s00253-018-9039-9

Castellón-Zelaya, M. F., and González-Martínez, S. (2021). Silage of the Organic Fraction of Municipal Solid Waste to Improve Methane Production. Water Sci. Technol. 83, 2536-2548. doi:10.2166/wst.2021.148 
Chalima, A., Taxeidis, G., and Topakas, E. (2020). Optimization of the Production of Docosahexaenoic Fatty Acid by the Heterotrophic Microalga Crypthecodinium Cohnii Utilizing a Dark Fermentation Effluent. Renew. Energ. 152, 102-109. doi:10.1016/j.renene.2020.01.041

Chanakya, H., and Shwetmala, K. (2017). Anaerobic Two Stage Degradation Pattern of Fermentable Components of Municipal Solid Waste. Glob. Nest J. 19, 706-715. doi:10.30955/gnj.002377

Chatterjee, B., and Mazumder, D. (2019). Role of Stage-Separation in the Ubiquitous Development of Anaerobic Digestion of Organic Fraction of Municipal Solid Waste: A Critical Review. Renew. Sustainable Energ. Rev. 104, 439-469. doi:10.1016/j.rser.2019.01.026

Chen, Y., Cheng, J. J., and Creamer, K. S. (2008). Inhibition of Anaerobic Digestion Process: A Review. Bioresour. Technol. 99, 4044-4064. doi:10.1016/ j.biortech.2007.01.057

Chen, X., Yuan, H., Zou, D., Liu, Y., Zhu, B., Chufo, A., et al. (2015). Improving Biomethane Yield by Controlling Fermentation Type of Acidogenic Phase in Two-phase Anaerobic Co-digestion of Food Waste and Rice Straw. Chem. Eng. J. 273, 254-260. doi:10.1016/j.cej.2015.03.067

Chen, H., Huang, R., Wu, J., Zhang, W., Han, Y., Xiao, B., et al. (2021). Biohythane Production and Microbial Characteristics of Two Alternating Mesophilic and Thermophilic Two-Stage Anaerobic Co-digesters Fed with Rice Straw and Pig Manure. Bioresour. Technol. 320, 124303. doi:10.1016/j.biortech.2020.124303

Chojnacka, K., Moustakas, K., and Witek-krowiak, A. (2020). Bio-based Fertilizers: A Practical Approach Towards Circular Economy. Bioresour. Technol. 295, 122223. doi:10.1016/j.biortech.2019.122223

Corbellini, V., Kougias, P. G., Treu, L., Bassani, I., Malpei, F., and Angelidaki, I. (2018). Hybrid Biogas Upgrading in a Two-Stage Thermophilic Reactor. Energ. Convers. Manage. 168, 1-10. doi:10.1016/j.enconman.2018.04.074

Dahiya, S., Kumar, A. N., Shanthi Sravan, J., Chatterjee, S., Sarkar, O., and Mohan, S. V. (2018). Food Waste Biorefinery: Sustainable Strategy for Circular Bioeconomy. Bioresour. Technol. 248, 2-12. doi:10.1016/j.biortech.2017.07.176

Dalkılıc, K., and Ugurlu, A. (2015). Biogas Production from Chicken Manure at Different Organic Loading Rates in a Mesophilic-Thermopilic Two Stage Anaerobic System. J. Biosci. Bioeng. 120, 315-322. doi:10.1016/ j.jbiosc.2015.01.021

Detman, A., Chojnacka, A., Błaszczyk, M., Kaźmierczak, W., Piotrowski, J., and Sikora, A. (2017). Biohydrogen and Biomethane (Biogas) Production in the Consecutive Stages of Anaerobic Digestion of Molasses. Pol. J. Environ. Stud. 26, 1023-1029. doi:10.15244/pjoes/68149

De Gioannis, G., Muntoni, A., Polettini, A., Pomi, R., and Spiga, D. (2017). Energy Recovery from One- and Two-Stage Anaerobic Digestion of Food Waste. Waste Manage. 68, 595-602. doi:10.1016/j.wasman.2017.06.013

Díaz, I., Fdz-Polanco, F., Mutsvene, B., and Fdz-Polanco, M. (2020). Effect of Operating Pressure on Direct Biomethane Production from Carbon Dioxide and Exogenous Hydrogen in the Anaerobic Digestion of Sewage Sludge. Appl. Energ. 280, 115915. doi:10.1016/j.apenergy.2020.115915

Ding, L., Chen, Y., Xu, Y., and Hu, B. (2021). Improving Treatment Capacity and Process Stability via a Two-Stage Anaerobic Digestion of Food Waste Combining Solid-State Acidogenesis and Leachate Methanogenesis/ recirculation. J. Clean. Prod. 279, 123644. doi:10.1016/j.jclepro.2020.123644

Enzmann, F., Gronemeier, D., and Holtmann, D. (2019). Process Stability Examinations of Bioelectromethanogenesis Using a Pure Culture of M. Maripaludis. Biochem. Eng. J. 151, 107321. doi:10.1016/j.bej.2019.107321

European Biogas Association (2019). EBA Statistical Report 2019. Brussels.

Falk, H. M., Reichling, P., Andersen, C., and Benz, R. (2015). Online Monitoring of Concentration and Dynamics of Volatile Fatty Acids in Anaerobic Digestion Processes with Mid-infrared Spectroscopy. Bioproc. Biosyst. Eng. 38, 237-249. doi:10.1007/s00449-014-1263-9

Fernández-Rodríguez, J., Pérez, M., and Romero, L. I. (2016). Semicontinuous Temperature-Phased Anaerobic Digestion (TPAD) of Organic Fraction of Municipal Solid Waste (OFMSW). Comparison with Single-Stage Processes. Chem. Eng. J. 285, 409-416. doi:10.1016/j.cej.2015.10.027

Flores-Cortés, M., Pérez-Trevilla, J., de María Cuervo-López, F., Buitrón, G., and Quijano, G. (2021). H2S Oxidation Coupled to Nitrate Reduction in a TwoStage Bioreactor: Targeting H2S-Rich Biogas Desulfurization. Waste Manage. 120, 76-84. doi:10.1016/j.wasman.2020.11.024

Fotidis, I. A., Treu, L., and Angelidaki, I. (2017). Enriched Ammonia-Tolerant Methanogenic Cultures as Bioaugmentation Inocula in Continuous
Biomethanation Processes. J. Clean. Prod. 166, 1305-1313. doi:10.1016/ j.jclepro.2017.08.151

Fraunhofer IEE (2018). Final Report on the ReBi 2.0 Project: Regulation of the Gas Production of Biogas Plants (ReBi) for Demand-Oriented, Controlled Generation of Electricity from Biogas: Transfer of Results from the Controlled Biogas Production from the Technical Scale to the Demonstration Plant. Goettingen.

Geppert, F., Liu, D., Weidner, E., and Heijne, A. t. (2019). Redox-flow Battery Design for a Methane-Producing Bioelectrochemical System. Int. J. Hydrogen Energ. 44, 21464-21469. doi:10.1016/j.ijhydene.2019.06.189

Ghanimeh, S., Al-Sanioura, D., Saikaly, P. E., and El-Fadel, M. (2019). Comparison of Single-Stage and Two-Stage Thermophilic Anaerobic Digestion of SSOFMSW during the Start-Up Phase. Waste Biomass Valor. 11, 6709-6716. doi:10.1007/s12649-019-00891-8

Ghimire, A., Luongo, V., Frunzo, L., Lens, P. N. L., Pirozzi, F., and Esposito, G. (2020). Biohythane Production from Food Waste in a Two-Stage Process: Assessing the Energy Recovery Potential. Environ. Technol. 1, 1-7. doi:10.1080/ 09593330.2020 .1869319

Gómez-Camacho, C. E., Pellicer Alborch, K., Bockisch, A., Neubauer, P., Junne, S., and Ruggeri, B. (2020). Monitoring the Physiological State in the Dark Fermentation of Maize/Grass Silage Using Flow Cytometry and Electrooptic Polarizability Measurements. Bioenerg. Res. doi:10.1007/s12155-020-10184-x

Hans, M., and Kumar, S. (2019). Biohythane Production in Two-Stage Anaerobic Digestion System. Int. J. Hydrogen Energ. 44, 17363-17380. doi:10.1016/ j.ijhydene.2018.10.022

Harper, S. R., and Pohland, F. G. (1986). Recent Developments in Hydrogen Management During Anaerobic Biological Wastewater Treatment. Biotechnol. Bioeng. 28, 585-602. doi:10.1002/bit.260280416

Heng, G. C., Isa, M. H., Lock, S. S. M., and Ng, C. A. (2021). Process Optimization of Waste Activated Sludge in Anaerobic Digestion and Biogas Production by Electrochemical Pre-treatment Using Ruthenium Oxide Coated Titanium Electrodes. Sustainability 13, 4874. doi:10.3390/su13094874

Huck, C., Poghossian, A., Wagner, P., and Schöning, M. J. (2013). Combined Amperometric/field-Effect Sensor for the Detection of Dissolved Hydrogen. Sensors Actuators B: Chem. 187, 168-173. doi:10.1016/j.snb.2012.10.050

International Energy Agency (2020). Germany 2020 Energy Policy Review. Paris.

Janzen, N. H., Schmidt, M., Krause, C., and Weuster-Botz, D. (2015). Evaluation of Fluorimetric $\mathrm{pH}$ Sensors for Bioprocess Monitoring at Low $\mathrm{pH}$. Bioproc. Biosyst. Eng. 38, 1685-1692. doi:10.1007/s00449-015-1409-4

Jie, W., Peng, Y., Ren, N., and Li, B. (2014). Volatile Fatty Acids (VFAs) Accumulation and Microbial Community Structure of Excess Sludge (ES) at Different pHs. Bioresour. Technol. 152, 124-129. doi:10.1016/ j.biortech.2013.11.011

Jimenez-Jorquera, C., Orozco, J., and Baldi, A. (2010). ISFET Based Microsensors for Environmental Monitoring. Sensors 10, 61-83. doi:10.3390/s100100061

Jiraprasertwong, A., Vichaitanapat, K., Leethochawalit, M., and Chavadej, S. (2018). Three-Stage Anaerobic Sequencing Batch Reactor (ASBR) for Maximum Methane Production: Effects of COD Loading Rate and Reactor Volumetric Ratio. Energies 11, 1543. doi:10.3390/en11061543

Jiraprasertwong, A., Maitriwong, K., and Chavadej, S. (2019). Production of Biogas from Cassava Wastewater Using a Three-Stage Upflow Anaerobic Sludge Blanket (UASB) Reactor. Renew. Energ. 130, 191-205. doi:10.1016/ j.renene.2018.06.034

Kaltschmitt, M., Hartmann, H., and Hofbauer, H. (2016). Energy from Biomass [in German]. Berlin, Heidelberg: Springer Berlin Heidelberg.

Kamyab, B., and Zilouei, H. (2021). Investigating the Efficiency of Biogas Production Using Modelling Anaerobic Digestion of baker's Yeast Wastewater on Two-Stage Mixed-UASB Reactor. Fuel 285, 119198. doi:10.1016/j.fuel.2020.119198

Kaye, G. W. C., and Laby, T. H. (1992). Tables of Physical and Chemical Constants and Some Mathematical Functions. Harlow, UK: Longman, 477.

Kim, S. W., Park, J. Y., Kim, J. K., Cho, J. H., Chun, Y. N., Lee, I. H., et al. (2000). Development of a Modified Three-Stage Methane Production Process Using Food Wastes. $A B A B$ 84-86, 731-742. doi:10.1385/ABAB:84-86:1-9:731

Kim, J. K., Oh, B. R., Chun, Y. N., and Kim, S. W. (2006). Effects of Temperature and Hydraulic Retention Time on Anaerobic Digestion of Food Waste. J. Biosci. Bioeng. 102, 328-332. doi:10.1263/jbb.102.328

Kim, J. K., Han, G. H., Oh, B. R., Chun, Y. N., Eom, C.-Y., and Kim, S. W. (2008). Volumetric Scale-Up of a Three Stage Fermentation System for Food Waste 
Treatment. Bioresour. Technol. 99, 4394-4399. doi:10.1016/ j.biortech.2007.08.031

Kleerebezem, R., Joosse, B., Rozendal, R., and van Loosdrecht, M. C. M. (2015). Anaerobic Digestion without Biogas?. Rev. Environ. Sci. Biotechnol. 14, 787-801. doi:10.1007/s11157-015-9374-6

Kobayashi, H., Nagashima, A., Kouyama, M., Fu, Q., Ikarashi, M., Maeda, H., et al. (2017). High-pressure Thermophilic Electromethanogenic System Producing Methane at $5 \mathrm{MPa}, 55^{\circ} \mathrm{C}$. J. Biosci. Bioeng. 124, 327-332. doi:10.1016/ j.jbiosc.2017.04.001

Kracke, F., Wong, A. B., Maegaard, K., Deutzmann, J. S., Hubert, M. A., Hahn, C., et al. (2019). Robust and Biocompatible Catalysts for Efficient HydrogenDriven Microbial Electrosynthesis. Commun. Chem. 2. doi:10.1038/s42004019-0145-0

Kracke, F., Deutzmann, J. S., Gu, W., and Spormann, A. M. (2020). In Situ Electrochemical H2 Production for Efficient and Stable Power-To-Gas Electromethanogenesis. Green. Chem. 22, 6194-6203. doi:10.1039/d0gc01894e

Kurahashi, K., Kimura, C., Fujimoto, Y., and Tokumoto, H. (2017). Value-adding Conversion and Volume Reduction of Sewage Sludge by Anaerobic Codigestion with Crude Glycerol. Bioresour. Technol. 232, 119-125. doi:10.1016/j.biortech.2017.02.012

Lecker, B., Illi, L., Lemmer, A., and Oechsner, H. (2017). Biological Hydrogen Methanation - A Review. Bioresour. Technol. 245, 1220-1228. doi:10.1016/ j.biortech.2017.08.176

Lemmer, A., Chen, Y., Lindner, J., Wonneberger, A. M., Zielonka, S., Oechsner, H., et al. (2015). Influence of Different Substrates on the Performance of a TwoStage High Pressure Anaerobic Digestion System. Bioresour. Technol. 178, 313-318. doi:10.1016/j.biortech.2014.09.118

Li, L., He, Q., Wei, Y., He, Q., and Peng, X. (2014). Early Warning Indicators for Monitoring the Process Failure of Anaerobic Digestion System of Food Waste. Bioresour. Technol. 171, 491-494. doi:10.1016/j.biortech.2014.08.089

Li, W., Guo, J., Cheng, H., Wang, W., and Dong, R. (2017). Two-phase Anaerobic Digestion of Municipal Solid Wastes Enhanced by Hydrothermal Pretreatment: Viability, Performance and Microbial Community Evaluation. Appl. Energ. 189, 613-622. doi:10.1016/j.apenergy.2016.12.101

Li, Z., Wachemo, A. C., Yuan, H., Korai, R. M., and Li, X. (2020). Improving Methane Content and Yield from Rice Straw by Adding Extra Hydrogen into a Two-Stage Anaerobic Digestion System. Int. J. Hydrogen Energ. 45, 3739-3749. doi:10.1016/j.ijhydene.2019.07.235

Li, L., Peng, X., Wang, X., and Wu, D. (2018). Anaerobic Digestion of Food Waste: A Review Focusing on Process Stability. Bioresour. Technol. 248, 20-28. doi:10.1016/j.biortech.2017.07.012

Li, W., Loh, K.-C., Zhang, J., Tong, Y. W., and Dai, Y. (2018). Two-stage Anaerobic Digestion of Food Waste and Horticultural Waste in High-Solid System. Appl. Energ. 209, 400-408. doi:10.1016/j.apenergy.2017.05.042

Li, Y., Li, L., Sun, Y., and Yuan, Z. (2018). Bioaugmentation Strategy for Enhancing Anaerobic Digestion of High $\mathrm{C} / \mathrm{N}$ Ratio Feedstock with Methanogenic Enrichment Culture. Bioresour. Technol. 261, 188-195. doi:10.1016/ j.biortech.2018.02.069

Linke, B., Rodríguez-Abalde, Á., Jost, C., and Krieg, A. (2015). Performance of a Novel Two-phase Continuously Fed Leach Bed Reactor for Demand-Based Biogas Production from maize Silage. Bioresour. Technol. 177, 34-40. doi:10.1016/j.biortech.2014.11.070

Liu, Y., Li, X., Kang, X., Yuan, Y., and Du, M. (2014). Short Chain Fatty Acids Accumulation and Microbial Community Succession during UltrasonicPretreated Sludge Anaerobic Fermentation Process: Effect of Alkaline Adjustment. Int. Biodeterior. Biodegrad. 94, 128-133. doi:10.1016/ j.ibiod.2014.07.004

Liu, H., Han, P., Liu, H., Zhou, G., Fu, B., and Zheng, Z. (2018). Full-scale Production of VFAs from Sewage Sludge by Anaerobic Alkaline Fermentation to Improve Biological Nutrients Removal in Domestic Wastewater. Bioresour. Technol. 260, 105-114. doi:10.1016/j.biortech.2018.03.105

Lovato, G., Albanez, R., Ruggero, L. S., Stracieri, L., Ratusznei, S. M., and Domingues Rodrigues, J. A. (2020). Energetic Feasibility of a Two-Stage Anaerobic Digestion System Compared to a Single-Stage System Treating Whey and Glycerin. Biochem. Eng. J. 161, 107653. doi:10.1016/ j.bej.2020.107653

Lowe, S. E., Jain, M. K., and Zeikus, J. G. (1993). Biology, Ecology, and Biotechnological Applications of Anaerobic Bacteria Adapted to
Environmental Stresses in Temperature, $\mathrm{pH}$, Salinity, or Substrates. Microbiol. Rev. 57, 451-509. doi:10.1128/mr.57.2.451-509.1993

Luo, G., and Angelidaki, I. (2013). Co-Digestion of Manure and Whey for In Situ Biogas Upgrading by the Addition of H(2): Process Performance and Microbial Insights. Appl. Microbiol. Biotechnol. 97, 1373-1381. doi:10.1007/s00253-0124547-5

Luo, G., Johansson, S., Boe, K., Xie, L., Zhou, Q., and Angelidaki, I. (2012). Simultaneous Hydrogen Utilization and In Situ Biogas Upgrading in an Anaerobic Reactor. Biotechnol. Bioeng. 109, 1088-1094. doi:10.1002/bit.24360

Lukitawesa, R., Wikandari, R., Millati, R., Taherzadeh, M. J., and Niklasson, C. (2018). Effect of Effluent Recirculation on Biogas Production Using Two-Stage Anaerobic Digestion of Citrus Waste. Molecules 23, 3380. doi:10.3390/ molecules 23123380

Markphan, W., Mamimin, C., Suksong, W., Prasertsan, P., and O-Thong, S. (2020). Comparative Assessment of Single-Stage and Two-Stage Anaerobic Digestion for Biogas Production from High Moisture Municipal Solid Waste. PeerJ 8, e9693. doi:10.7717/peerj.9693

Mayer, F., Enzmann, F., Lopez, A. M., and Holtmann, D. (2019). Performance of Different Methanogenic Species for the Microbial Electrosynthesis of Methane from Carbon Dioxide. Bioresour. Technol. 289, 121706. doi:10.1016/ j.biortech.2019.121706

Meegoda, J., Li, B., Patel, K., and Wang, L. (2018). A Review of the Processes, Parameters, and Optimization of Anaerobic Digestion. Ijerph 15, 2224. doi:10.3390/ijerph15102224

Menzel, T., Neubauer, P., and Junne, S. (2020). Role of Microbial Hydrolysis in Anaerobic Digestion. Energies 13, 5555. doi:10.3390/en13215555

Merkle, W., Baer, K., Lindner, J., Zielonka, S., Ortloff, F., Graf, F., et al. (2017). Influence of Pressures up to $50 \mathrm{Bar}$ on Two-Stage Anaerobic Digestion. Bioresour. Technol. 232, 72-78. doi:10.1016/j.biortech.2017.02.013

Micolucci, F., and Uellendhal, H. (2018). Two-Stage Dry Anaerobic Digestion Process Control of Biowaste for Hydrolysis and Biogas Optimization. Chem. Eng. Technol. 41, 717-726. doi:10.1002/ceat.201700467

Moeller, L., and Zehnsdorf, A. (2016). Process Upsets in a Full-Scale Anaerobic Digestion Bioreactor: Over-acidification and Foam Formation during Biogas Production. Energ Sustain. Soc. 6, 30. doi:10.1186/s13705-016-0095-7

Moestedt, J., Nordell, E., Hallin, S., and Schnürer, A. (2016). Two-stage Anaerobic Digestion for Reduced Hydrogen Sulphide Production. J. Chem. Technol. Biotechnol. 91, 1055-1062. doi:10.1002/jctb.4682

Morozova, I., Nikulina, N., Oechsner, H., Krümpel, J., and Lemmer, A. (2020). Effects of Increasing Nitrogen Content on Process Stability and Reactor Performance in Anaerobic Digestion. Energies 13, 1139. doi:10.3390/ en13051139

Muha, I., Zielonka, S., Lemmer, A., Schönberg, M., Linke, B., Grillo, A., et al. (2013). Do Two-phase Biogas Plants Separate Anaerobic Digestion Phases? - A Mathematical Model for the Distribution of Anaerobic Digestion Phases Among Reactor Stages. Bioresour. Technol. 132, 414-418. doi:10.1016/ j.biortech.2012.12.031

Mutungwazi, A., Ijoma, G. N., and Matambo, T. S. (2021). The Significance of Microbial Community Functions and Symbiosis in Enhancing Methane Production During Anaerobic Digestion: A Review. Symbiosis 83, 1-24. doi:10.1007/s13199-020-00734-4

Nery, E. W., and Kubota, L. T. (2016). Integrated, Paper-Based Potentiometric Electronic Tongue for the Analysis of Beer and Wine. Anal. Chim. Acta 918, 60-68. doi:10.1016/j.aca.2016.03.004

Nespeca, M. G., Rodrigues, C. V., Santana, K. O., Maintinguer, S. I., and de Oliveira, J. E. (2017). Determination of Alcohols and Volatile Organic Acids in Anaerobic Bioreactors for H 2 Production by Near Infrared Spectroscopy. Int. J. Hydrogen Energ. 42, 20480-20493. doi:10.1016/j.ijhydene.2017.07.044

Nsair, A., Onen Cinar, S., Alassali, A., Abu Qdais, H., and Kuchta, K. (2020). Operational Parameters of Biogas Plants: A Review and Evaluation Study. Energies 13, 3761. doi:10.3390/en13153761

Nzila, A. (2017). Mini Review: Update on Bioaugmentation in Anaerobic Processes for Biogas Production. Anaerobe 46, 3-12. doi:10.1016/j.anaerobe.2016.11.007

Okoro-Shekwaga, C. K., Ross, A. B., and Camargo-Valero, M. A. (2019). Improving the Biomethane Yield from Food Waste by Boosting Hydrogenotrophic Methanogenesis. Appl. Energ. 254, 113629. doi:10.1016/j.apenergy.2019.113629

O-Thong, S. (2018). "Biohythane Production from Organic Wastes by Two-Stage Anaerobic Fermentation Technology," in Advances In Biofuels And Bioenergy. 
Editor C. Mamimin (Rijeka, Croatia: IntechOpen), 83-116. doi:10.5772/ intechopen.74392

Paillet, F., Barrau, C., Escudié, R., Bernet, N., and Trably, E. (2021). Robust Operation Through Effluent Recycling for Hydrogen Production from the Organic Fraction of Municipal Solid Waste. Bioresour. Technol. 319, 124196. doi:10.1016/j.biortech.2020.124196

Pandey, P. K., and Soupir, M. L. (2011). Escherichia coli Inactivation Kinetics in Anaerobic Digestion of Dairy Manure Under Moderate, Mesophilic and Thermophilic Temperatures. AMB Express 1, 18. doi:10.1186/2191-0855-1-18

Patel, A., Mahboubi, A., Horváth, I. S., Taherzadeh, M. J., Rova, U., Christakopoulos, P., et al. (2021). Volatile Fatty Acids (VFAs) Generated by Anaerobic Digestion Serve as Feedstock for Freshwater and Marine Oleaginous Microorganisms to Produce Biodiesel and Added-Value Compounds. Front. Microbiol. 12, 614612. doi:10.3389/fmicb.2021.614612

Pavlostathis, S. G. (2011). "Kinetics and Modeling of Anaerobic Treatment and Biotransformation Processes," in Comprehensive Biotechnology. Editor M. Moo-Young (Burlington, MA: Academic Press), 385-397. doi:10.1016/ b978-0-08-088504-9.00385-8

Peters, L., Uhlenhut, F., Biernacki, P., and Steinigeweg, S. (2018). Aktueller Stand der Flexibilisierungskonzepte von Biogasanlagen zur Abdeckung der Residuallast. Chem. Ingenieur Technik 90, 36-46. doi:10.1002/cite.201700101

Pfeiffer, W., Nguyen, V. T., Neumann, J., Awe, D., and Tränckner, J. (2020). Operation and Control of a Full-Scale Biogas Plant Treating Wastewater from the Cleaning of Car Tanks. Chem. Eng. Technol. 43, 84-94. doi:10.1002/ ceat. 201900398

Postawa, K. (2018). Novel Solutions in Modeling of Anaerobic Digestion Process Two-phase AD Models Development and Comparison. Int. J. Chem. Reactor Eng. 16. doi:10.1515/ijcre-2017-0139

Qin, Y., Li, L., Wu, J., Xiao, B., Hojo, T., Kubota, K., et al. (2019). Co-production of Biohydrogen and Biomethane from Food Waste and Paper Waste via Recirculated Two-phase Anaerobic Digestion Process: Bioenergy Yields and Metabolic Distribution. Bioresour. Technol. 276, 325-334. doi:10.1016/ j.biortech.2019.01.004

Rabii, A., Aldin, S., Dahman, Y., and Elbeshbishy, E. (2019). A Review on Anaerobic Co-digestion with a Focus on the Microbial Populations and the Effect of Multi-Stage Digester Configuration. Energies 12, 1106. doi:10.3390/ en 12061106

Rachbauer, L., Beyer, R., Bochmann, G., and Fuchs, W. (2017). Characteristics of Adapted Hydrogenotrophic Community During Biomethanation. Sci. Total Environ. 595, 912-919. doi:10.1016/j.scitotenv.2017.03.074

Rajendran, K., Mahapatra, D., Venkatraman, A. V., Muthuswamy, S., and Pugazhendhi, A. (2020). Advancing Anaerobic Digestion Through TwoStage Processes: Current Developments and Future Trends. Renew. Sustainable Energ. Rev. 123, 109746. doi:10.1016/j.rser.2020.109746

Rani, W., Sriwuryandari, L., Priantoro, E. A., and Sintawardani, N. (2020). Shockadaptation in a Three-Stage Anaerobic Reactor Treating Tofu Whey Wastewater. IOP Conf. Ser. Earth Environ. Sci. 483, 012033. doi:10.1088/ 1755-1315/483/1/012033

Reddy, M. V., Hayashi, S., Choi, D., Cho, H., and Chang, Y.-C. (2018). Short Chain and Medium Chain Fatty Acids Production Using Food Waste Under Nonaugmented and Bio-Augmented Conditions. J. Clean. Prod. 176, 645-653. doi:10.1016/j.jclepro.2017.12.166

Renda, R., Gigli, E., Cappelli, A., Simoni, S., Guerriero, E., and Romagnoli, F. (2016). Economic Feasibility Study of a Small-Scale Biogas Plant Using a TwoStage Process and a Fixed Bio-Film Reactor for a Cost-Efficient Production. Energ. Proced. 95, 385-392. doi:10.1016/j.egypro.2016.09.042

Robinson, J. A., and Tiedje, J. M. (1982). Kinetics of Hydrogen Consumption by Rumen Fluid, Anaerobic Digestor Sludge, and Sediment. Appl. Environ. Microbiol. 44, 1374-1384. doi:10.1128/aem.44.6.1374-1384.1982

Rosgaard, L., Andric, P., Dam-Johansen, K., Pedersen, S., and Meyer, A. S. (2007). Effects of Substrate Loading on Enzymatic Hydrolysis and Viscosity of Pretreated Barley Straw. Appl. Biochem. Biotechnol. 143, 27-40. doi:10.1007/ s12010-007-0028-1

Salsali, H., Parker, W., and Sattar, S. (2005). Influence of Staged Operation of Mesophilic Anaerobic Digestion on Microbial Reduction. Proc. Water Environ. Fed. 2005, 4571-4586. doi:10.2175/193864705783866676

Sarkar, O., Butti, S. K., and Venkata Mohan, S. (2017). Acidogenesis Driven by Hydrogen Partial Pressure Towards Bioethanol Production Through
Fatty Acids Reduction. Energy 118, 425-434. doi:10.1016/ j.energy.2016.12.017

Schievano, A., Tenca, A., Scaglia, B., Merlino, G., Rizzi, A., Daffonchio, D., et al. (2012). Two-stage vs Single-Stage Thermophilic Anaerobic Digestion: Comparison of Energy Production and Biodegradation Efficiencies. Environ. Sci. Technol. 46, 8502-8510. doi:10.1021/es301376n

Sensfuss, F., and Pfluger, B. (2014). Optimized Pathways Towards Ambitious Climate protection in the European Electricity System. Karlsruhe.

Slezak, R., Grzelak, J., Krzystek, L., and Ledakowicz, S. (2017). The Effect of Initial Organic Load of the Kitchen Waste on the Production of VFA and H 2 in Dark Fermentation. Waste Manage. 68, 610-617. doi:10.1016/j.wasman.2017.06.024

Song, H., Choi, O., Pandey, A., Kim, Y. G., Joo, J. S., and Sang, B.-I. (2019). Simultaneous Production of Methane and Acetate by Thermophilic Mixed Culture from Carbon Dioxide in Bioelectrochemical System. Bioresour. Technol. 281, 474-479. doi:10.1016/j.biortech.2019.02.115

Srisowmeya, G., Chakravarthy, M., and Nandhini Devi, G. (2020). Critical Considerations in Two-Stage Anaerobic Digestion of Food Waste - A Review. Renew. Sustainable Energ. Rev. 119, 109587. doi:10.1016/ j.rser.2019.109587

Sträuber, H., Schröder, M., and Kleinsteuber, S. (2012). Metabolic and Microbial Community Dynamics during the Hydrolytic and Acidogenic Fermentation in a Leach-Bed Process. Energ Sustain. Soc. 2, 13. doi:10.1186/2192-0567-2-13

Theuerl, S., Herrmann, C., Heiermann, M., Grundmann, P., Landwehr, N., Kreidenweis, U., et al. (2019). The Future Agricultural Biogas Plant in Germany: A Vision. Energies 12, 396. doi:10.3390/en12030396

Tijani, H., Yuzir, A., and Abdullah, N. (2018). Producing Desulfurized Biogas Using Two-Stage Domesticated Shear-Loop Anaerobic Contact Stabilization System. Waste Manage. 78, 770-780. doi:10.1016/j.wasman.2018.06.045

Urriza-Arsuaga, I., Bedoya, M., and Orellana, G. (2019). Tailored Luminescent Sensing of NH3 in Biomethane Productions. Sensors Actuators B: Chem. 292, 210-216. doi:10.1016/j.snb.2019.04.109

Van, D. P., Fujiwara, T., Leu Tho, B., Song Toan, P. P., and Hoang Minh, G. (2020). A Review of Anaerobic Digestion Systems for Biodegradable Waste: Configurations, Operating Parameters, and Current Trends. Environ. Eng. Res. 25, 1-17. doi:10.4491/eer.2018.334

Vega De Lille, M., Forstner, J., Groß, F., Benning, R., and Delgado, A. (2016). Modeling the Two-Stage Anaerobic Digestion of Domestic Wastewater with the Development of a Monitoring Application. Braz. J. Chem. Eng. 33, 801-815. doi:10.1590/0104-6632.20160334s20150150

Wan, C., and Li, Y. (2012). Fungal Pretreatment of Lignocellulosic Biomass. Biotechnol. Adv. 30, 1447-1457. doi:10.1016/j.biotechadv.2012.03.003

Wang, S., Hawkins, G. L., Kiepper, B. H., and Das, K. C. (2018). Treatment of Slaughterhouse Blood Waste Using Pilot Scale Two-Stage Anaerobic Digesters for Biogas Production. Renew. Energ. 126, 552-562. doi:10.1016/ j.renene.2018.03.076

Wang, Y., Wang, Z., Zhang, Q., Li, G., and Xia, C. (2020). Comparison of BioHydrogen and Bio-Methane Production Performance in Continuous Twophase Anaerobic Fermentation System Between Co-digestion and Digestate Recirculation. Bioresour. Technol. 318, 124269. doi:10.1016/ j.biortech.2020.124269

Wirth, R., Kovács, E., Maróti, G., Bagi, Z., Rákhely, G., and Kovács, K. L. (2012). Characterization of a Biogas-Producing Microbial Community by Short-Read Next Generation DNA Sequencing. Biotechnol. Biofuels 5, 41. doi:10.1186/ 1754-6834-5-41

Wu, L.-J., Kobayashi, T., Li, Y.-Y., and Xu, K.-Q. (2015). Comparison of SingleStage and Temperature-Phased Two-Stage Anaerobic Digestion of Oily Food Waste. Energ. Convers. Manage. 106, 1174-1182. doi:10.1016/ j.enconman.2015.10.059

Wu, Q.-L., Guo, W.-Q., Zheng, H.-S., Luo, H.-C., Feng, X.-C., Yin, R.-L., et al. (2016). Enhancement of Volatile Fatty Acid Production by Co-fermentation of Food Waste and Excess Sludge Without pH Control: The Mechanism and Microbial Community Analyses. Bioresour. Technol. 216, 653-660. doi:10.1016/j.biortech.2016.06.006

Wu, D., Li, L., Zhao, X., Peng, Y., Yang, P., and Peng, X. (2019). Anaerobic Digestion: A Review on Process Monitoring. Renew. Sustainable Energ. Rev. 103, 1-12. doi:10.1016/j.rser.2018.12.039

Yan, B. H., Selvam, A., and Wong, J. W. C. (2020). Bio-hydrogen and Methane Production from Two-phase Anaerobic Digestion of Food Waste Under the 
Scheme of Acidogenic Off-Gas Reuse. Bioresour. Technol. 297, 122400. doi:10.1016/j.biortech.2019.122400

Yun, Y.-M., Sung, S., Shin, H.-S., Han, J.-I., Kim, H.-W., and Kim, D.-H. (2017). Producing Desulfurized Biogas Through Removal of Sulfate in the First-Stage of a Two-Stage Anaerobic Digestion. Biotechnol. Bioeng. 114, 970-979. doi:10.1002/bit.26233

Zhang, B., Zhang, L.-L., Zhang, S.-C., Shi, H.-Z., and Cai, W.-M. (2005). The Influence of $\mathrm{pH}$ on Hydrolysis and Acidogenesis of Kitchen Wastes in Twophase Anaerobic Digestion. Environ. Technol. 26, 329-340. doi:10.1080/ 09593332608618563

Zhang, J., Loh, K.-C., Li, W., Lim, J. W., Dai, Y., and Tong, Y. W. (2017). Threestage Anaerobic Digester for Food Waste. Appl. Energ. 194, 287-295. doi:10.1016/j.apenergy.2016.10.116

Zhang, S., Chang, J., Liu, W., Pan, Y., Cui, K., Chen, X., et al. (2018). A Novel Bioaugmentation Strategy to Accelerate Methanogenesis via Adding Geobacter Sulfurreducens PCA in Anaerobic Digestion System. Sci. Total Environ. 642, 322-326. doi:10.1016/j.scitotenv.2018.06.043

Zhang, L., Kuroki, A., Loh, K.-C., Seok, J. K., Dai, Y., and Tong, Y. W. (2020). Highly Efficient Anaerobic Co-digestion of Food Waste and Horticultural Waste Using a Three-Stage Thermophilic Bioreactor: Performance Evaluation, Microbial Community Analysis, and Energy Balance Assessment. Energ. Convers. Manage. 223, 113290. doi:10.1016/ j.enconman.2020.113290

Zhao, Q., and Liu, Y. (2019). Is Anaerobic Digestion a Reliable Barrier for Deactivation of Pathogens in Biosludge? Sci. Total Environ. 668, 893-902. doi:10.1016/j.scitotenv.2019.03.063

Zheng, G., Liu, J., Shao, Z., and Chen, T. (2020). Emission Characteristics and Health Risk Assessment of VOCs from a Food Waste Anaerobic Digestion
Plant: A Case Study of Suzhou, China. Environ. Pollut. 257, 113546. doi:10.1016/j.envpol.2019.113546

Zhou, L., and Boyd, C. E. (2016). Comparison of Nessler, Phenate, Salicylate and Ion Selective Electrode Procedures for Determination of Total Ammonia Nitrogen in Aquaculture. Aquaculture 450, 187-193. doi:10.1016/j.aquaculture.2015.07.022

Zosel, J., Schelter, M., Oelßner, W., and Zimmermann, P. (2011). Final Report of the Joint Project: Process Optimization of Biogas Production by Means of Innovative Measuring and Control Technology for the Detection of Dissolved Hydrogen as a Microbial Key Intermediat (BINERWA). Available at: https:// www.fnr-server.de/ftp/pdf/berichte/22009407.pdf (Accessed April 8, 2021).

Conflict of Interest: The authors declare that the research was conducted in the absence of any commercial or financial relationships that could be construed as a potential conflict of interest.

Publisher's Note: All claims expressed in this article are solely those of the authors and do not necessarily represent those of their affiliated organizations, or those of the publisher, the editors and the reviewers. Any product that may be evaluated in this article, or claim that may be made by its manufacturer, is not guaranteed or endorsed by the publisher.

Copyright (C) 2021 Janesch, Pereira, Neubauer and Junne. This is an open-access article distributed under the terms of the Creative Commons Attribution License (CC $B Y)$. The use, distribution or reproduction in other forums is permitted, provided the original author(s) and the copyright owner(s) are credited and that the original publication in this journal is cited, in accordance with accepted academic practice. No use, distribution or reproduction is permitted which does not comply with these terms. 